\title{
The persistence of a chlorophyll spectral biosignature from Martian evaporite and spring analogues under Mars-like conditions
}

\author{
J. M. Stromberg' , D. M. Applin², E. A. Cloutis², M. Rice ${ }^{3}$, G. Berard ${ }^{4}$ and P. Mann² \\ ${ }^{1}$ Department of Earth Sciences, Center for Planetary Science and Exploration, University of Western Ontario, \\ 1151 Richmond Street, London, Ontario, Canada N6A 3 K7 \\ e-mail: jstromb@uwo.ca \\ ${ }^{2}$ Department of Geography, Hyperspectral Optical Sensing for Extraterrestrial Reconnaissance Laboratory, \\ University of Winnipeg, 515 Portage Avenue, Winnipeg, Manitoba, Canada R3B 2E9 \\ ${ }^{3}$ Division of Geological and Planetary Sciences, California Institute of Technology, MC 150-21, Pasadena, CA 91125, USA \\ ${ }^{4}$ Department of Geography, Geosciences Laboratory for Environmental Analysis and Decision-Making, University of \\ Winnipeg, 515 Portage Avenue, Winnipeg, Manitoba, Canada R3B 2 E9
}

\begin{abstract}
Spring and evaporite deposits are considered two of the most promising environments for past habitability on Mars and preservation of biosignatures. Manitoba, Canada hosts the East German Creek (EGC) hypersaline spring complex, and the post impact evaporite gypsum beds of the Lake St. Martin (LSM) impact. The EGC complex has microbial mats, sediments, algae and biofabrics, while endolithic communities are ubiquitous in the LSM gypsum beds. These communities are spectrally detectable based largely on the presence of a chlorophyll absorption band at $670 \mathrm{~nm}$; however, the robustness of this feature under Martian surface conditions was unclear. Biological and biology-bearing samples from EGC and LSM were exposed to conditions similar to the surface of present day Mars (high UV flux, $100 \mathrm{mbar}$, anoxic, $\mathrm{CO}_{2}$ rich) for up to 44 days, and preservation of the $670 \mathrm{~nm}$ chlorophyll feature and chlorophyll red-edge was observed. A decrease in band depth of the $670 \mathrm{~nm}$ band ranging from $\sim 16$ to $80 \%$ resulted, with correlations seen in the degree of preservation and the spatial proximity of samples to the spring mound and mineral shielding effects. The spectra were deconvolved to Mars Exploration Rover (MER) Pancam and Mars Science Laboratory (MSL) Mastcam science filter bandpasses to investigate the detectability of the $670 \mathrm{~nm}$ feature and to compare with common mineral features. The red-edge and $670 \mathrm{~nm}$ feature associated with chlorophyll can be distinguished from the spectra of minerals with features below $\sim 1000 \mathrm{~nm}$, such as hematite and jarosite. However, distinguishing goethite from samples with the chlorophyll feature is more problematic, and quantitative interpretation using band depth data makes little distinction between iron oxyhydroxides and the $670 \mathrm{~nm}$ chlorophyll feature. The chlorophyll spectral feature is observable in both Pancam and Mastcam, and we propose that of the proposed EXOMARS Pancam filters, the PHYLL filter is best suited for its detection.
\end{abstract}

Received 1 July 2013, accepted 5 October 2013, first published online 17 December 2013

Keywords: Biosignatures, Mars Analogue, Reflectance Spectroscopy, Chlorophyll, Pancam, Mastcam, ExoMars, Evaporites, Spring Deposits, Oxyhydroxides.

\section{Introduction}

While in its past, Mars is believed to have had warm and wet surface conditions, at least intermittently, with the potential to harbour life (Mustard et al. 2008; Squyres et al. 2012), the present surface is hostile to life as we know it (Bibring et al. 2005; Johnson et al. 2011). The search for evidence of past life on Mars requires the identification of regions of past habitable conditions as well as biomarkers that can withstand the harsh present Martian surface conditions (Summons et al. 2011). Present characterization of the Martian surface is primarily conducted by remote spectroscopic sensing whose design and mandate is not the search for evidence of life [e.g. Mars Reconnaissance Orbiter (MO), Compact Reconnaissance Imaging Spectrometer for Mars (CRISM), Mars Exploration Rover (MER) (Pancam), Mars Science Laboratory (MSL) (Mastcam, ChemCam in passive mode)]. However, many of these instruments have potential for detecting biomolecules, and an understanding of the limitations of these techniques for biomarker detection and the effects of Martian surface conditions on biomarker degradation is integral to determining whether these assets are capable of detecting evidence of life.

\section{Martian habitability}

It is unlikely that there is near-surface extant life presently on Mars due to high levels of ultraviolet (UV) irradiation, low temperatures and pressures, as well as oxidative and desiccating conditions (Kminek \& Bada 2006; Dartnell et al. 2007; Johnson et al. 2011; Gómez et al. 2012), however, in its history it may have possessed more habitable conditions (Farmer \& Des Marais 1999; Cockell et al. 2000; Summons et al. 2011). The Noachian era of Mars' history was warmer and wetter than present day, as evidenced by accumulations of 
phyllosilicates, carbonates and sulphates (Squyres et al. 2004, 2012; Gendrin et al. 2005; Mustard et al. 2008; Murchie et al. 2009; Rice et al. 2010; Elhmann \& Mustard 2012), implying the past presence of water, which is essential to carbon-based life as it is currently understood.

However, as the climate shifted to the current colder, drier Mars, fewer regions of the planet remained habitable and life would have been forced into niches in which it was shielded from the harsh surface conditions. Proposed environments for the last vestiges of life on Mars include Noachian evaporite and spring deposits (Rothschild 1990; Grasby et al. 2003; Manicelli et al. 2004; Grasby \& Londry 2007; Summons et al. 2011). Both types of deposits imply the presence of saline waters that may have been present on or near the surface for extended periods of time. In addition, spring deposits may have been host to potentially warm and energy- or nutrient-rich waters where life could have persisted as Mars transitioned into its present less hospitable state (Grasby et al. 2003; Manicelli et al. 2004; Grasby \& Londry 2007). The characterization of sulphate minerals in these Noachian deposits will make it possible to assess past and current habitability as well as biosignature preservation potential (King \& McLennan 2010), as some terrestrial sulphates have been shown to preserve organic biosignatures and microfossils on geologically relevant timescales (Aubrey et al. 2006; Schopf et al. 2012).

\section{Organic biomarker preservation}

Organic biomarkers are defined as the molecular skeletons of lipid and pigment biomolecules which are specific enough in their molecular structure and biological distribution that they are useful taxonomic indicator molecules (Buick 2008). This includes compounds such as the photosynthetic and UV-protectant pigments, chlorophyll and carotenoids, which have been suggested to be ideal biosignatures as they are easily detectable by spectroscopic methods (Seager et al. 2005; Marshall et al. 2006). While these are all highly specialized and evolved molecules, the ubiquity of UV-VIS radiation as both a threat for life and an energy source throughout our universe does not preclude their potential evolution (WynnWilliams et al. 2002). Neither does it exclude their relevance to astrobiology as their potential as biosignatures has been recognized within the field of astrobiology and widely studied (e.g. Wynn-Williams et al. 2002; Marshall et al. 2006; Parnell et al. 2007; Dartnell et al. 2011; Dartnell et al. 2012). However, it is necessary to acknowledge that this is a highly earth-centric view of the potential for life and biosignatures on other planets and should be viewed as such. However, it remains crucial for the search for biosignatures on Mars to create a database of biosignatures from terrestrial primitive life forms (Marshall et al. 2006).

The greatest challenge to detecting biomarkers within the context of Mars exploration is not the ability to detect them if present, but identifying regions and mineral assemblages in which they may be preserved. The primary factors affecting the potential for long-term fossil preservation in Martian paleoenvironments include the stability of the primary mineral assemblage and the subsequent degree of weathering and diagenesis that the deposit has undergone (Cady et al. 2003). When considering these factors, both mineralizing springs, such as those proposed for Arabia Terra (Allen \& Oehler 2008), and evaporitic salt deposits are among those Martian paleoenvironments with the highest preservation potential for fossil biosignatures (Farmer \& Des Marais 1999; Summons et al. 2011). This is also consistent with laboratory data that confirms the stability of many sulphate minerals under present Martian surface conditions (Cloutis et al. 2007).

Sulphate evaporite minerals and spring deposits on Earth have been proposed as relevant analogues for the search for extant life on Mars due to their potential for biosignature preservation (Barbieri \& Stivaletta 2011; Gómez et al. 2012; Berard et al. 2013). Evaporites have been found to preserve biosignatures in the form of amino acids and their degradation products (Aubrey et al. 2006), and by the entrapment of halophiles in fluid inclusions in modern systems (Foster $e t$ al. 2010), and on geologically relevant timescales from 3500 years to 250 million years (Vreeland et al. 2000; Schubert et al. 2009). In hypersaline and other extreme conditions, life is often found in endolithic niches, which provide organisms with a protective UV-shielding effect, and temperature and water activity moderation from harsh exterior conditions (Rothschild 1990; Hughes \& Lawley 2003; Weirzchos et al. 2006; Cockell et al. 2008). Depending on the optical properties of the host rock, they can be found up to $10 \mathrm{~mm}$ in depth (Hughes \& Lawley 2003). It is for this reason that communities like these are found in the most extreme environments on Earth, from the Atacama Desert to the high Arctic and Antarctic (Friedmann 1982; Cockell et al. 2002; Hughes \& Lawley 2003; Weirzchos et al. 2006; Stivaletta et al. 2010).

In addition to providing refuge from harmful UV-radiation, evaporite precipitation can provide preservation from oxidative surface processes (Stivaletta \& Barbieri 2009), as well as desiccation due to the fact that gypsum does not dehydrate under Martian conditions (Cloutis et al. 2007). It should also be noted that while it has been shown experimentally that Martian levels of UV-irradiation results in a high kill rate, this loss in cell viability does not directly correlate with the destruction of detectable biomolecules, so it may be possible that some biomolecules may remain intact beyond the time of cell death and represent viable biomarkers (Cockell et al. 2005).

\section{Spectroscopy of biomarkers and chlorophyll}

The biomolecule chlorophyll (Fig. 1) is a photosynthetic pigment that is present in cyanobacteria, algae and higher order plants. Chlorophyll exists in many varieties, with the most common being the terrestrially ubiquitous chlorophyll $a$, which is made up of a chlorin ring with a central magnesium $(\mathrm{Mg})$ ion, methyl side chains and a hydrocarbon tail. Chlorophyll is what is known as a polyene molecule, meaning that is has alternating single and double bonds which result in strong absorptions in the visible (VIS) spectrum and peak molar absorption coefficient of $10^{5} \mathrm{M}^{-1} \mathrm{~cm}^{-1}$, which is among the highest for organic compounds (Berg et al. 2002). The chlorin ring is formed of quinones, which can form in the 


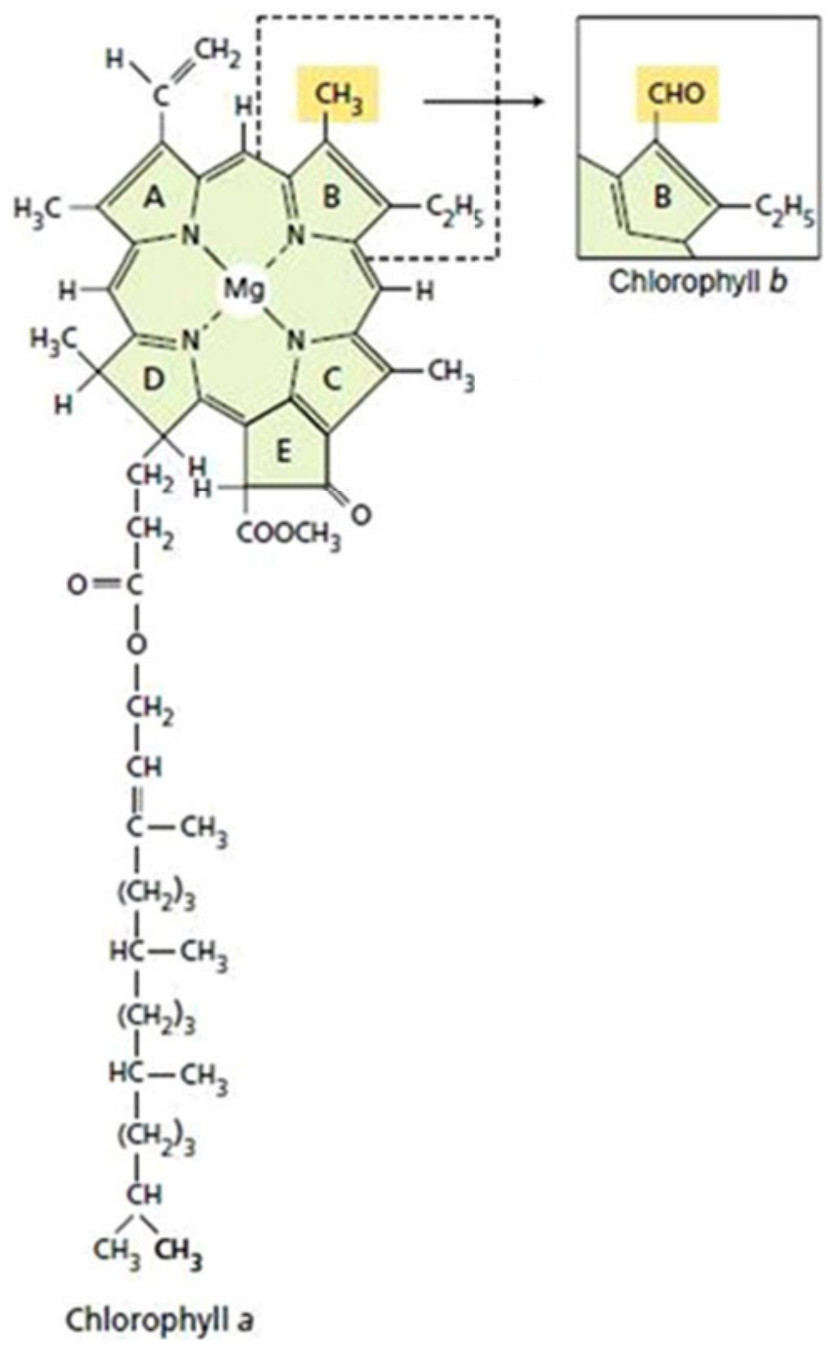

Fig. 1. Chlorophyll molecular structure. The chlorophylls have a porphyrin-like ring structure with a magnesium $(\mathrm{Mg})$ atom coordinated in the center and a long hydrophobic tail. The porphyrinlike ring is the site of the electron rearrangements that occur when Chl is excited. Chlorophylls differ in the substituents around the rings and the pattern of double bonds (Adapted from Taiz and Zeager, 2010).

interstellar media (Bernstein et al. 1999). Chlorophyll may therefore be a universally evolved and available molecule (Parnell 2005). As such, it has been identified as a very detectable molecular biomarker (Parnell et al. 2007), and has been characterized as a biosignature relevant to Mars (e.g., Vishnivetskaya et al. 2003; Edwards et al. 2004; Parnell 2005; Bishop et al. 2006; Dartnell et al. 2010; Gomez et al. 2011). Additionally, the breakdown products of chlorophyll and porphyrins have been identified as stable and geologically persistent molecules (Baker \& Louda 1986; Parnell et al. 2007) that are detectable using a variety of methods (Suo et al. 2007).

While chlorophyll in exposed cyanobacteria is susceptible to degradation by ionizing radiation and loses is spectral properties (Dartnell et al. 2011), the role of an endolithic niche and mineral shielding has yet to be explored with UV/VIS reflectance spectroscopy, as most work was focused on Raman and infrared (IR) spectroscopy (Wynn-Williams et al. 2002;
Marshall et al. 2006; Pullan et al. 2008; Foster et al. 2010). The UV/VIS $(300-2500 \mathrm{~nm})$ spectral region is relevant as it corresponds to the wavelengths $(\sim 400-1000 \mathrm{~nm})$ of MER's Pancam, MSL's Mastcam and the proposed spectroscopic cameras for the ExoMars mission (Table 1) (Bell et al. 2003; Cousins et al. 2010, 2012), and pigments such as chlorophyll absorb strongly in the visible spectrum and have unique spectral signatures (Berg et al. 2002). As well, visible to nearinfrared (VIS-NIR) reflectance spectroscopy is useful for biosignature identification because it allows us to probe both vibrational and electronic processes, as opposed to relying solely on vibrational information. With this combination, interpretations can be made regarding the mineralogical (Table 2) and biogenic characteristics of our targets.

\section{Study sites}

\section{Lake St. Martin crater evaporite deposit}

The Lake St. Martin (LSM) impact structure is a circular $\sim 23 \mathrm{~km}$ diameter impact structure located in central Manitoba, Canada (Fig. 2). The LSM impact structure formed $\sim 228 \mathrm{Ma}$ (Schmieder et al. 2013), when a hypervelocity (Janssens et al. 1977; Bannatyne \& McCabe 1984) asteroid collided with $\sim 400-500 \mathrm{~m}$ of Ordovician and Devonian sandstones, shales and carbonates superimposed on Archaean-aged granite (McCabe \& Bannatyne 1970). The impact resulted in the near-total volatilization of the carbonates and the melting of granite (McCabe \& Bannatyne 1970), creating a complex crater with a central peak (Bannatyne \& McCabe 1984). Present crater depth is $\sim 320 \mathrm{~m}$, however prior to glacial modification the crater depth may have been up to $610 \mathrm{~m}$ (McCabe \& Bannatyne 1970).

The intracrater evaporite member of interest overlies a red bed member (Fe-stained coarse sediments) and is a $43 \mathrm{~m}$ sequence of gypsum/anhydrite, minor glauberite and occasional interbedded clays (Bannatyne 1959; McCabe \& Bannatyne 1970). The gypsum/anhydrite deposits are of unknown age, although the regional evaporite upper Amaranth formation, which has been identified as Jurassic, is often inferred to have concurrent deposition (McCabe \& Bannatyne 1970), although not without controversy (Leybourne et al. 2007). An open-pit gypsum mine in the area has exposed a continuous $\sim 5 \mathrm{~km}$ long section of the gypsum/anhydrite deposit, of up to $15 \mathrm{~m}$ vertical exposure. The exposed gypsum exhibits highly variable grain size and bedding morphology, a variety of textures similar to those observed on Mars by the Opportunity and Curiosity rovers (Cloutis et al. 2011), glacial morphological modification expressed as drag folds (Wardlaw et al. 1969), solution collapse structures, and sometimes complex folding, perhaps due to hydration of primary anhydrite. Stratified endolithic communities are observed ubiquitously throughout the gypsum deposit, primarily concentrated in gypsum boulders and variably in the gypsum mine faces.

Recent imagery has identified hydrated sulphates in several Martian craters (e.g., Wray et al. 2011; Squyres et al. 2012). Impact crater evaporite deposits could potentially contain 
Table 1. Wavelength (in $\mathrm{nm}$ ) of band centres of 'Geology' multispectral filters for cameras on present and proposed Mars Missions. The 554 and $640 \mathrm{~nm}$ Mastcam filters are the Bayer filters (Bell et al. 2003; Bell et al. 2012; Cousins et al. 2010, 2012).

\begin{tabular}{|c|c|c|c|c|c|c|c|}
\hline \multirow[b]{2}{*}{ MER Pancam } & \multirow[b]{2}{*}{ MSL Mastcam } & \multicolumn{6}{|c|}{ Proposed Exomars } \\
\hline & & PHYLL & SULF & FERRIC & MAFIC & ALL Fe & HYDRA \\
\hline 436 & 450 & 440 & 440 & 440 & 440 & 440 & 440 \\
\hline 482 & 495 & 510 & 470 & 500 & 470 & 490 & 500 \\
\hline 535 & 527 & 560 & 500 & 530 & 520 & 520 & 550 \\
\hline 601 & 554 & 590 & 560 & 570 & 560 & 570 & 590 \\
\hline 673 & 640 & 650 & 610 & 610 & 640 & 590 & 630 \\
\hline 754 & 676 & 680 & 660 & 670 & 690 & 700 & 710 \\
\hline 803 & 751 & 730 & 700 & 740 & 740 & 740 & 760 \\
\hline 864 & 805 & 770 & 730 & 780 & 780 & 780 & 810 \\
\hline 904 & 867 & 810 & 820 & 840 & 840 & 840 & 890 \\
\hline 934 & 908 & 900 & 890 & 900 & 900 & 890 & 940 \\
\hline \multirow[t]{2}{*}{1009} & 937 & 960 & 950 & 950 & 950 & 950 & 970 \\
\hline & 1012 & 1000 & 1000 & 1000 & 1000 & 1000 & 1000 \\
\hline
\end{tabular}

Table 2. Spectral features of pure gypsum in the UVIVIS/ NIR region (Cloutis et al. 2006). The $1000 \mathrm{~nm}(2 v 1+v 3)$ hydration feature is important in Pancam/Mastcam spectra of gypsum (Rice et al. 2010; Squyres et al. 2012)

\begin{tabular}{ll}
\hline Feature & Wavelength position of Minima (nm) \\
\hline Weak $\mathrm{H}_{2} \mathrm{O}$ overtones & 1000,1150 \\
$\mathrm{H}_{2} \mathrm{O}$ overtones/combinations & $1390,1449,1488,1534$ \\
$\mathrm{H}_{2} \mathrm{O}$ Combinations & 1944,1977 \\
Combinations of $\mathrm{OH}$ or & $1751,17580,217,2220,243,2550$ \\
$\mathrm{H}_{2} \mathrm{O}$ bending, stretching & \\
and rotation fundamentals & \\
or $\mathrm{S}-\mathrm{O}$ bending overtones & \\
\hline
\end{tabular}

fossils, well-preserved climate record, and endoliths, as such features are found in terrestrial crater-hosted gypsum deposits (Spencer 2000; Stivaletta et al. 2005). Given the presence of microbial activity in the gypsum at the LSM impact crater and the diversity of rock types and terrains, it is a useful analogue environment for understanding the possible presence and preservation of biomarkers.

\section{East German creek hypersaline spring system}

A series of analogues for low-temperature spring deposits for Mars, such as those tentatively identified in Vernal Crater (Allen \& Oehler 2008), exists near the western shore of Lake Winnipegosis in west-central Manitoba, Canada $\left(52^{\circ} 45^{\prime} \mathrm{N}\right.$, $100^{\circ} 53^{\prime} \mathrm{W}$ ) (Berard et al. 2013). East German Creek (EGC) is one of a number of hypersaline spring complexes that are currently being deposited on Devonian carbonate reefs. The dissolved salts are a result of the injection of basal melt water during the Pleistocene glaciation (Grasby \& Londry 2007). The basin groundwater re-established northeast flow after the retreat of the glacier, which results in the injected cold, mineralrich mixture of glacial and meteoritic water being deposited as salt flats on the surface (Grasby 2000).

The analogy is the expression of surface mineralogy and morphology, which is the result of the extrusion of briney groundwater. The carbonate reefs are the conduit at EGC; layered sedimentary deposits on Mars are inferred to facilitate groundwater flow and/or seepage, which could act similarly. Since we can only infer with little information at the character of the subsurface systems of potential spring deposits on Mars, the surficial expression is used for identification and characterization as an analogue site. EGC has been extensively characterized as a Mars-analogue site (Berard et al. 2013), as have other terrestrial spring deposits with similar subsurface systems (Battler et al. 2013a, b). These systems are relevant as Mars likely once had relatively large amounts of surface water (e.g. Head et al. 1999) and widespread glaciation (e.g. Baker et al. 1991; Fassett et al. 2010), the possibility of considerable amounts of groundwater/ground ice (e.g. Burr et al. 2002; Head et al. 2009), and most importantly, the presence of layered sedimentary units (e.g. Malin \& Edgett 2000; Gendrin et al. 2005; Rossi et al. 2008). Therefore, the requisites for the development of cold saline spring systems were once present. The distribution of possible spring deposits has been extensively reviewed (Rossi et al. 2008), and some of these putative deposits may be as young as $10 \mathrm{Myr}$.

EGC is characterized by a variety of vents up to $2 \mathrm{~m}$ across and $0.5 \mathrm{~m}$ higher than the surrounding salt flat (Fig. 3). The vents are lined by fine siliceous flour and various $\mathrm{Fe}$ oxyhydroxides as well as the eukaryotic blue-green algae, Percursaria percura that in some cases appear red in colour due to the presence of amorphous iron clumps associated with the algal filaments (Grasby \& Londry 2007). Spring mounds in which the vents occur are up to $10 \mathrm{~m}$ in diameter and gradually grade into surrounding outwash plains (making their dimensions difficult to determine). Well-consolidated Fe-stained tufa pebbles precipitate from solution forming an extensive pavement adjacent to the spring mounds. This pavement, especially close to the spring mounds, contains extensive coatings of goethite on surficial materials. Further into the outwash plain there is exposed fragmented bedrock that exhibits extensive salt water weathering. Regions of high water flow are host to a complex cyanobacteria-dominated microbial mat system and sediments that are rich in sulphate reducing bacteria and other heterotrophs (Grasby \& Londry 2007). 


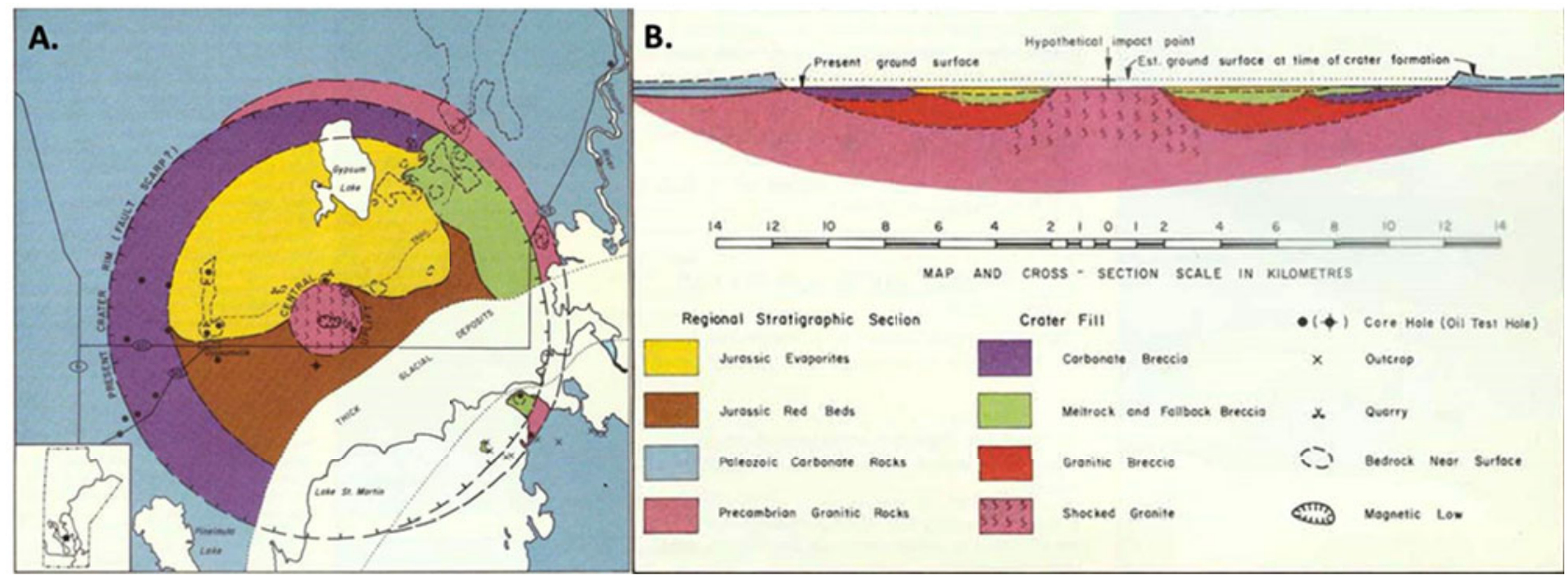

Fig. 2. A. Lake St. Martin impact structure. B. Postulated true-scale cross section. Gypsum evaporite deposits are shown in yellow. (Adapted from Bannatyne and McCabe, 1984)

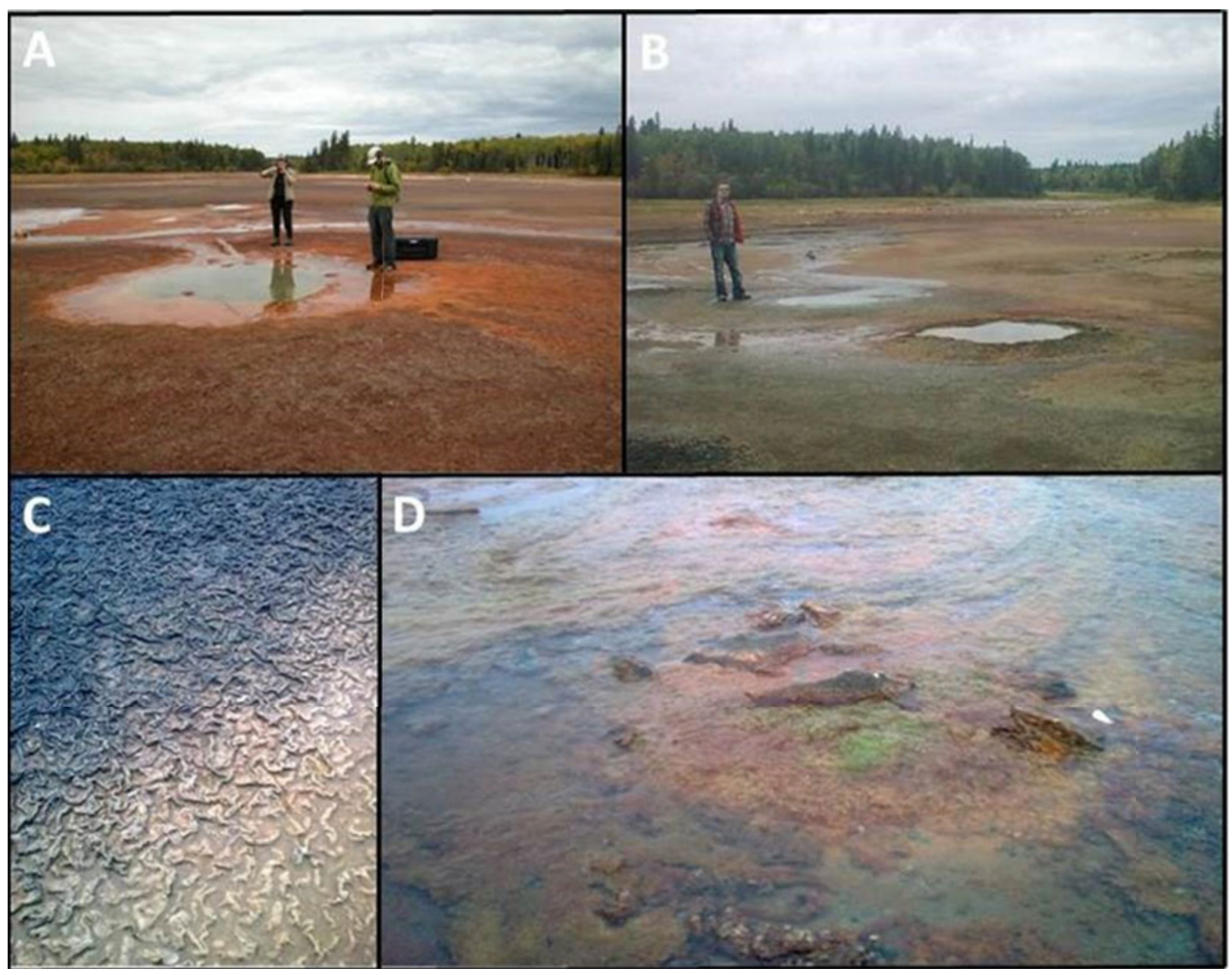

Fig. 3. East German Creek site characteristics: A. Spring mound, pronounced Fe staining. B. Spring mound. C. White and black 'brains'. D. Algae mats.

Ground-level photographs of the site from 1914 (Cole 1915), and air photos from 1948 and 2001, show that there have been no significant changes in extent of spring mounds or flow rates at EGC over the last $\sim 100$ years. Given these systems have likely been present since the reversal of basinal waterflow $\sim 8000$ years ago, they may be stable on geological 


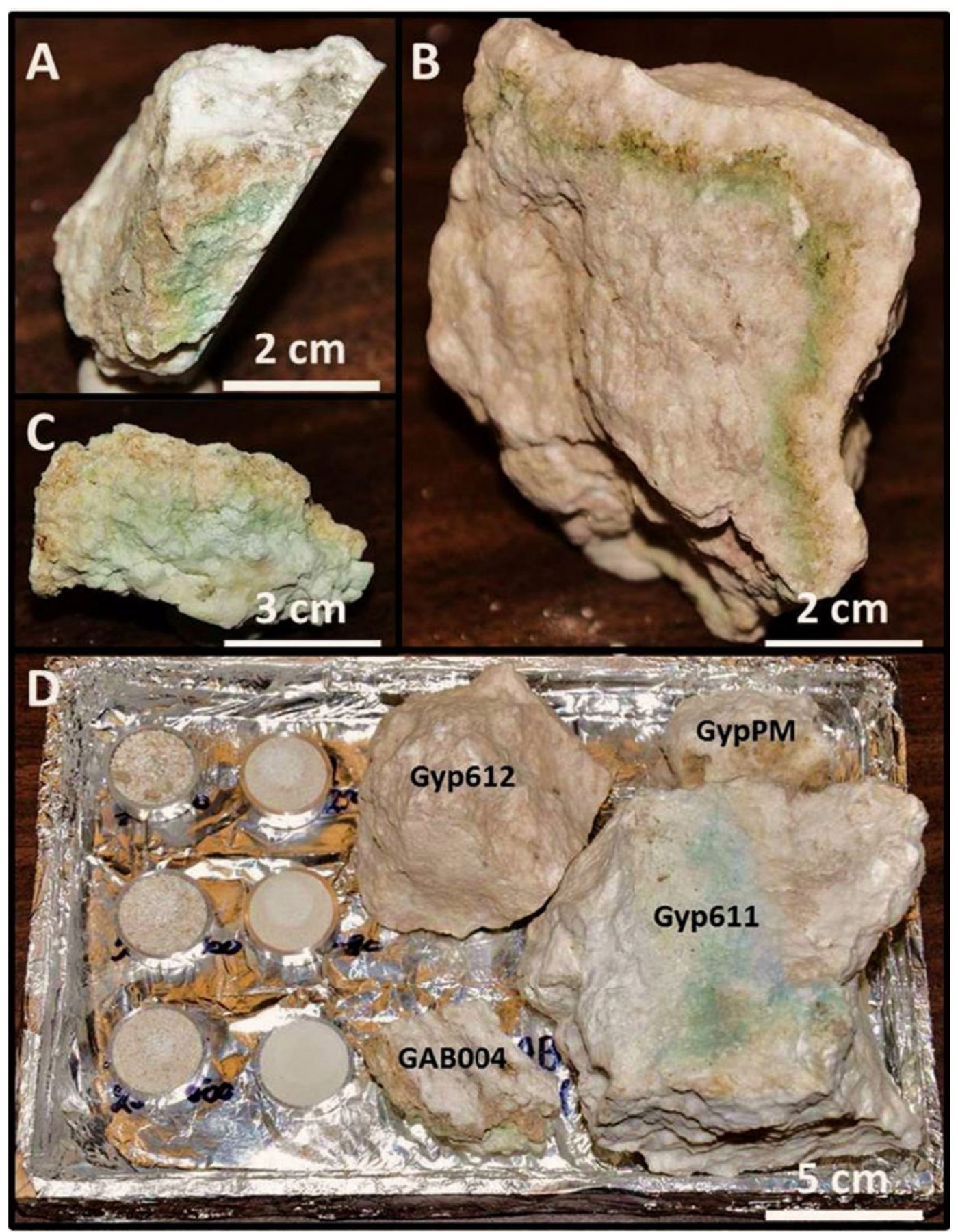

Fig. 4. Gypsum hosted endolith samples. A. GypPM with orange and green layers. B. Gyp612 with green layer. C. GAB004 with green and orange layers. D. All samples after removal from the environmental chamber for spectral analysis, and subjected to UV irradiation from above (GYP611 blue and green layers exposed at surface).

timescales. There has been extensive regional isostatic rebound over this period (Lambert et al. 1998); therefore the absence of changes to the complex during this time also suggests that barring significant geologic phenomena or basinal flow cessation, these low-temperature hypersaline springs could provide surface and near-surface mineral-rich liquid water for an extended period of time (Berard et al. 2013). This also suggests that these features, tentatively identified on Mars, could have provided a persistent refuge for life as the planet cooled and dried, and should be high priority in the search for evidence of extinct or extant life on Mars.

\section{Methods}

Sampling and exposure to Mars surface-like conditions

Gypsumville 2010

Gypsum samples were collected from a gypsum quarry within the LSM impact structure in September 2010 in 
an area of scattered gypsum boulders at the coordinates $51^{\circ} 46.792^{\prime} \mathrm{N}, 98^{\circ} 37.811^{\prime} \mathrm{W}$. The boulders were likely the remnants of mining activities which ceased in the area in the 1930s. All samples were broken off with a rock hammer or scraped with a scoopula into plastic bags and transported to the University of Winnipeg for analysis.

For spectral analysis, the most brightly coloured fragments of the sample GAB004 were crushed and dry sieved into the following grain sizes: 45-90, 90-250, 250-500, 500-1000, $>1000 \mu \mathrm{m}$. The larger GYPPM sample was cut with a diamond-tipped rock saw to obtain a fresh cut surface and expose the endoliths (Fig. 4).

All samples were placed in an anoxic vacuum chamber and flushed with $\mathrm{CO}_{2}$ with an open container of Drierite desiccant, and irradiated by a $25 \mathrm{~W}$ deuterium lamp; $\mathrm{CO}_{2}$ pressure was maintained at $100 \mathrm{mb}$ for 40 days to simulate Mars surface conditions. Spectral data were collected at days $0,4,11,18,25$, 32 and 40.

\section{East German Creek 2010}

Samples were collected from the main spring (Big Cauldron) and from additional sample stations along the primary outflow channel through the outwash plains. The spring was sampled for algae and sediment, and samples of microbial mats were cut out beside the outflow channel at intervals of $\sim 50 \mathrm{~m}$ from the spring (sites 5-12). The outwash plain was also sampled for its two unique 'brain' textures (algal mats with or without surficial precipitated minerals), white and black in colour (Fig. 3). All samples were collected into hard-sided plastic containers and covered with spring water to maintain moisture during transport to the University of Winnipeg. Once there, the samples were kept in an environmental chamber with an alternating dark/light cycle to try to maintain in situ conditions until initial spectral analysis 2 days later. The samples were then placed in a vacuum chamber with a beaker of Drierite desiccant and exposed to a $25 \mathrm{~W}$ deuterium lamp and $100 \mathrm{mb}$ of $\mathrm{CO}_{2}$ for 44 days. Spectral data were collected prior to, and after the 44 days of desiccation.

\section{East German Creek 2011}

Outwash plain sediments were collected at variable distances from Big Cauldron. Site choices were based on visible differences in colour and texture (Fig. 5). The samples were collected in the form of $\sim 20 \times 10 \times 5 \mathrm{~cm}$ thick bricks extracted with a knife and shovel. The samples were air dried and then exposed to a low pressure (13 Mbar), $\mathrm{CO}_{2}$ atmosphere for 30 days prior to post-drying spectral measurements. UV irradiation was not implemented, as we determined it to be less significant of a factor than atmospheric pressure and composition, based on the two previous experimental runs.

\section{UV irradiation}

UV irradiation was provided by $25 \mathrm{~W}$ DO802 deuterium lamp (Heraeus Noblelight, Germany). Illumination was directed at the samples with an in-house aluminium fixture. The samples

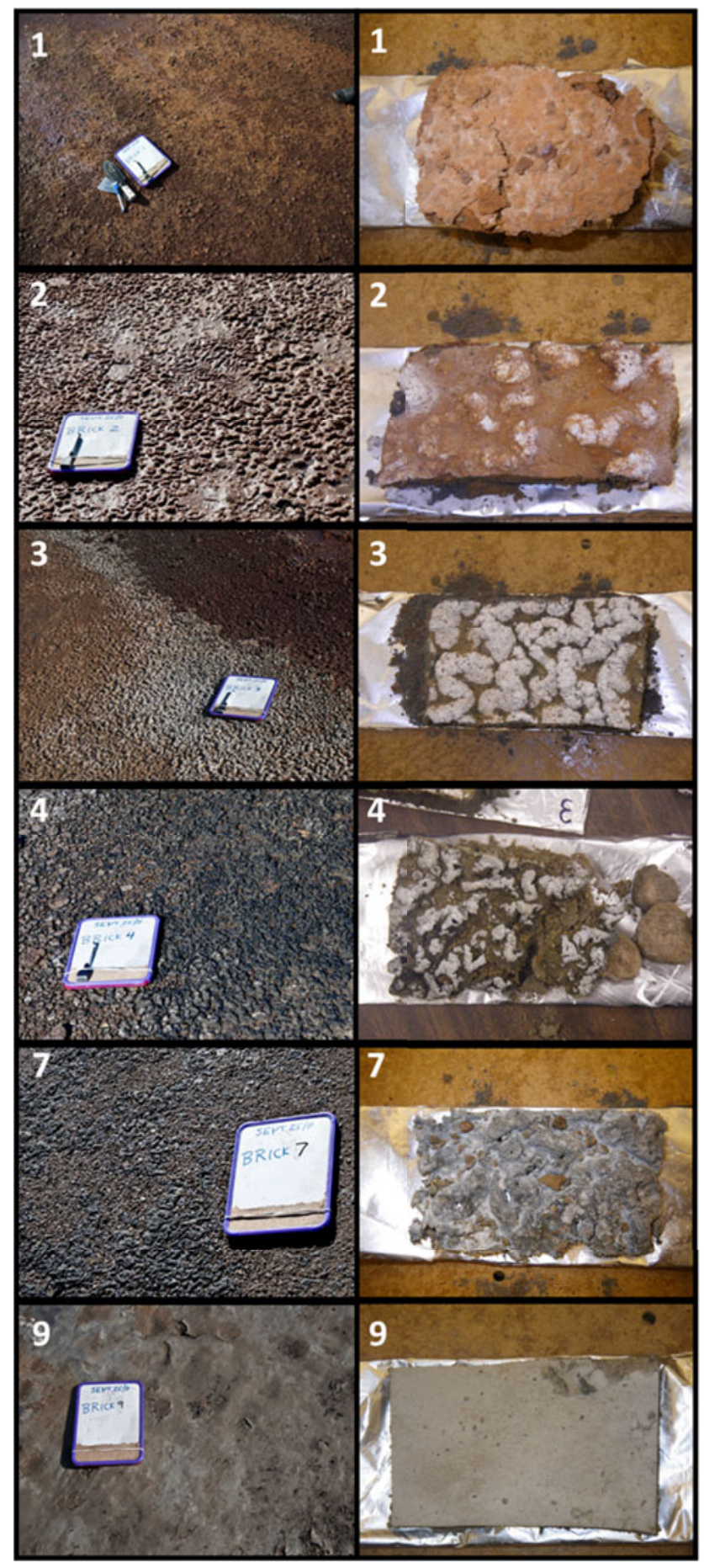

Fig. 5. East German Creek 2011 outwash plain samples sites and corresponding samples post dessication. Samples are $20 \times 10 \times 5 \mathrm{~cm}$ and numbers correspond to sample numbers.

were also housed in an aluminium casing to maximize absorbed dose. Lamp output peaks in the deep UVC and tails off into the UVB and UVA regions. Total irradiance over the UV regions was calculated as: UVC $200-279 \mathrm{~nm}$ $\left(15933 \mathrm{~W} \mathrm{~m}^{-2}, \quad 57360 \mathrm{~kJ} \mathrm{~m}^{-2} \mathrm{~h}^{-1}\right), \quad$ UVB $\quad 280-315 \mathrm{~nm}$ $\left(2772 \mathrm{~W} \mathrm{~m}^{-2}, \quad 9981 \mathrm{~kJ} \mathrm{~m}^{-2} \mathrm{~h}^{-1}\right)$ and UVA $316-400 \mathrm{~nm}$ $\left(3077 \mathrm{~W} \mathrm{~m}^{-2}, 11078 \mathrm{~kJ} \mathrm{~m}^{-2} \mathrm{~h}^{-1}\right)$. Using the daily Mars UV 
fluence modelled by Cockell et al. (2000), the total laboratory daily fluence of UVC + UVB irradiation provided by our lamp at a distance of $\sim 75 \mathrm{~mm}$ from the samples is roughly equal to $\sim 6.8$ Mars years. This corresponds to $\sim 300$ Mars years for a 44 day run. To understand how many years of incident photons this simulates for the gypsum hosted endolith communities at LSM (and chlorophyll embedded in mineral precipitates at EGC), transmission spectra of a $2 \mathrm{~mm}$ thick piece of gypsum, which covered an endolithic community from LSM was acquired. Spectra were acquired with the same deuterium lamp used for sample irradiance, directed through $6400 \mu \mathrm{m}$ diameter solarization-resistant fibres, with transmission efficiencies between 23 and $40 \%$ across the $200-400 \mathrm{~nm}$ range. The end of this bundle was placed $\sim 2 \mathrm{~mm}$ from the gypsum, and a closely similar pickup fibre was placed $\sim 2 \mathrm{~mm}$ from the other side of the gypsum. The fibre bundles were placed close to the gypsum sample, rather than the distance used during sample irradiance, to increase the signal-to-noise ratio, which is greatly reduced by increasing path length in UV spectroscopy for ex-vacuo experiments. The pickup fibre was directed into the detector array of an Ocean Optics Maya2000 Pro, a high resolution $(0.47 \mathrm{~nm})$ spectrometer with high quantum efficiency, and a collection range of $200-1100 \mathrm{~nm}$. Dark current spectra (input to spectrometer blocked), reference spectra (measurement collected without gypsum in between fibre bundles), and transmission spectra were acquired with a $13 \mathrm{~ms}$ integration time, and averaging of 200 individual spectra. The measurements show transmission values as $\sim 0.1 \%$ at $200 \mathrm{~nm}, \sim 0.05 \%$ at $250 \mathrm{~nm}$ and $\sim 0.15 \%$ at $400 \mathrm{~nm}$. The extremely low values at $250 \mathrm{~nm}$ are likely due to trace ferrous iron content. Considering these transmission values, our UV irradiation on samples with fully exposed chlorophyll simulates 20000-60000 Mars-years of UV radiation for chlorophyll at $\sim 2 \mathrm{~mm}$ below the surface. For samples with chlorophyll not fully exposed (some mineral coating) during the experiment, the UV irradiation simulates between 300 and 20000 Mars-years, depending on coating thickness. These numbers are assuming that chlorophyll decomposition is fully controlled by UV flux rather than lower atmospheric pressure; therefore they represent maximum values.

Given these lengths of time do not represent a geologic timescale, it is pertinent to discuss how it is relevant to Martian evaporite and spring deposits. With evaporative brine that is in-filling an impact crater, there will likely be periodic episodes of desiccate conditions followed by subsequent deposition. If these mineral deposits (e.g. gypsum) were to host chlorophyll bearing photosynthetic endolithic communities (such as those present at LSM), there could be multi-layered chlorophyll deposition. In a situation such as this, our study simulates exposure at the surface for at maximum 300 Mars-years, and at a depth of $2 \mathrm{~mm}$ in gypsum for 60000 Mars-years before movement to further depth. A similar situation can be presented with cold water saline spring deposits. Periodic deposition would certainly cover chlorophyll that has been deposited, and if a spring was active (which has been discussed as a possibility on geologic timescaled (Berard et al. 2013), the chlorophyll would likely be exposed for only a short amount of

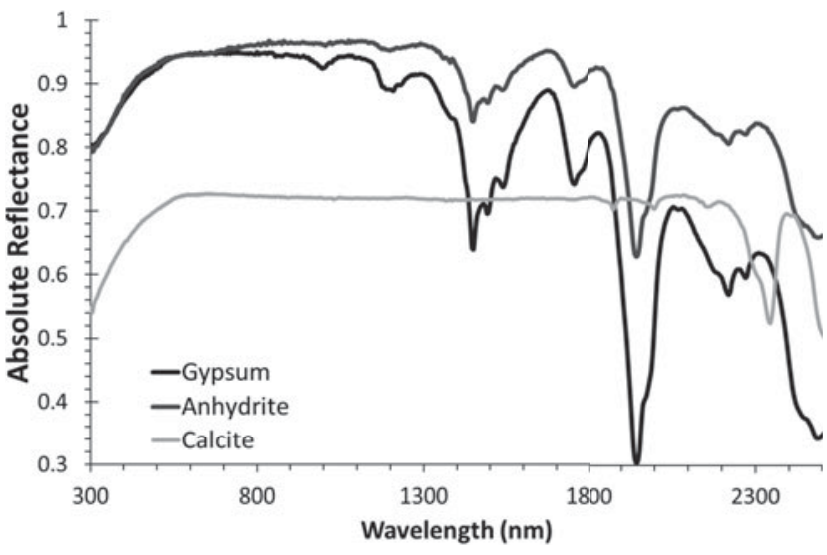

Fig. 6. RELAB reflectance spectra of pure minerals from the HOSERLab database showing the $\sim 1100 \mathrm{~nm}$ hydration feature in gypsum that is lost in dehydration to anhydrite, as well as the $\sim 2300 \mathrm{~nm}$ carbonate feature in calcite.

time. The pervasive iron oxyhydroxide staining present at many terrestrial spring systems, including EGC, would allow much less UV photon transmission than gypsum alone, and likely none to the very near surface. Therefore we conclude that if depositional environments such as the two we present here existed on Mars, there is the likelihood that chlorophyll (if it was present) could be present in the near surface if it is stable through our experiments.

\section{Spectral analysis}

Reflectance spectra over the 350-2500 nm range were acquired at HOSERLab (Cloutis et al. 2006) with an Analytical Spectral Devices FieldSpec Pro HR ${ }^{\circledR}$ spectrophotometer. The spectral resolution of the instrument varies between 2 and $7 \mathrm{~nm}$ and spectral sampling is done at $1.4 \mathrm{~nm}$ intervals. The data are internally resampled by the instrument to $1 \mathrm{~nm}$ intervals. Spectra were acquired at $i=30^{\circ}$ and $e=0^{\circ}$ with illumination provided by an in-house $100 \mathrm{~W}$ quartz-tungsten-halogen light source. A total of between 200 and 1000 spectra were averaged to improve the signal-to-noise ratio. Reflectance spectra were measured relative to a calibrated Labsphere (New Hampshire, USA) Spectralon ${ }^{\circledR}$ disk. The spot size measured by this instrument is variable, depending on the chosen distance between the sample and fibre optic probe. For this study, a spot size of 5 (endoliths) to 20 (biofabrics and sediments) $\mathrm{mm}$ diameter was utilized. The larger spot size for the biofabrics and sediments was used in order to get more representative spectra, as the samples are largely heterogenous. Samples were removed from the environment chamber for spectral analysis, and all possible measures were taken to reduce the amount of time spent out of the chamber.

The ASD spectrometer has three detectors that collectively cover the full $350-2500 \mathrm{~nm}$ range. There may be offsets in the data where the detector changeovers occur $(1000$ and $1830 \mathrm{~nm}$ ). These offsets were removed by correcting the shortest (350-1000 nm) and longest (1830-2500 nm) intervals to the middle interval $(1000-1830 \mathrm{~nm})$, which is 

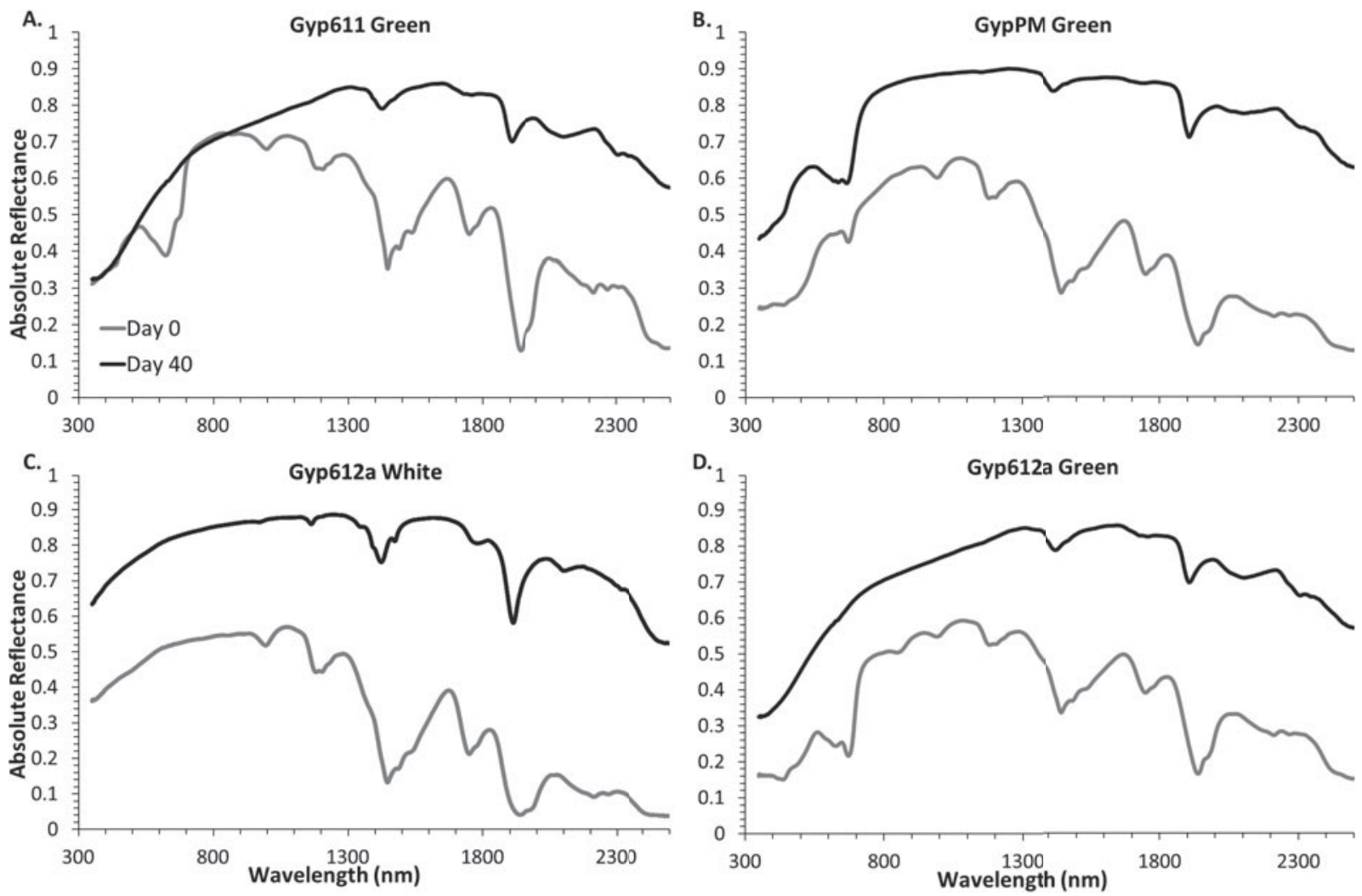

Fig. 7. Reflectance spectra of gypsum endoliths exposed at surface vs. mineral shielded (A,B), and pure gypsum vs. and endolithic community (C,D) prior to and following 40 days of dessication under Mars like conditions. See Fig. 4 for sample photos.
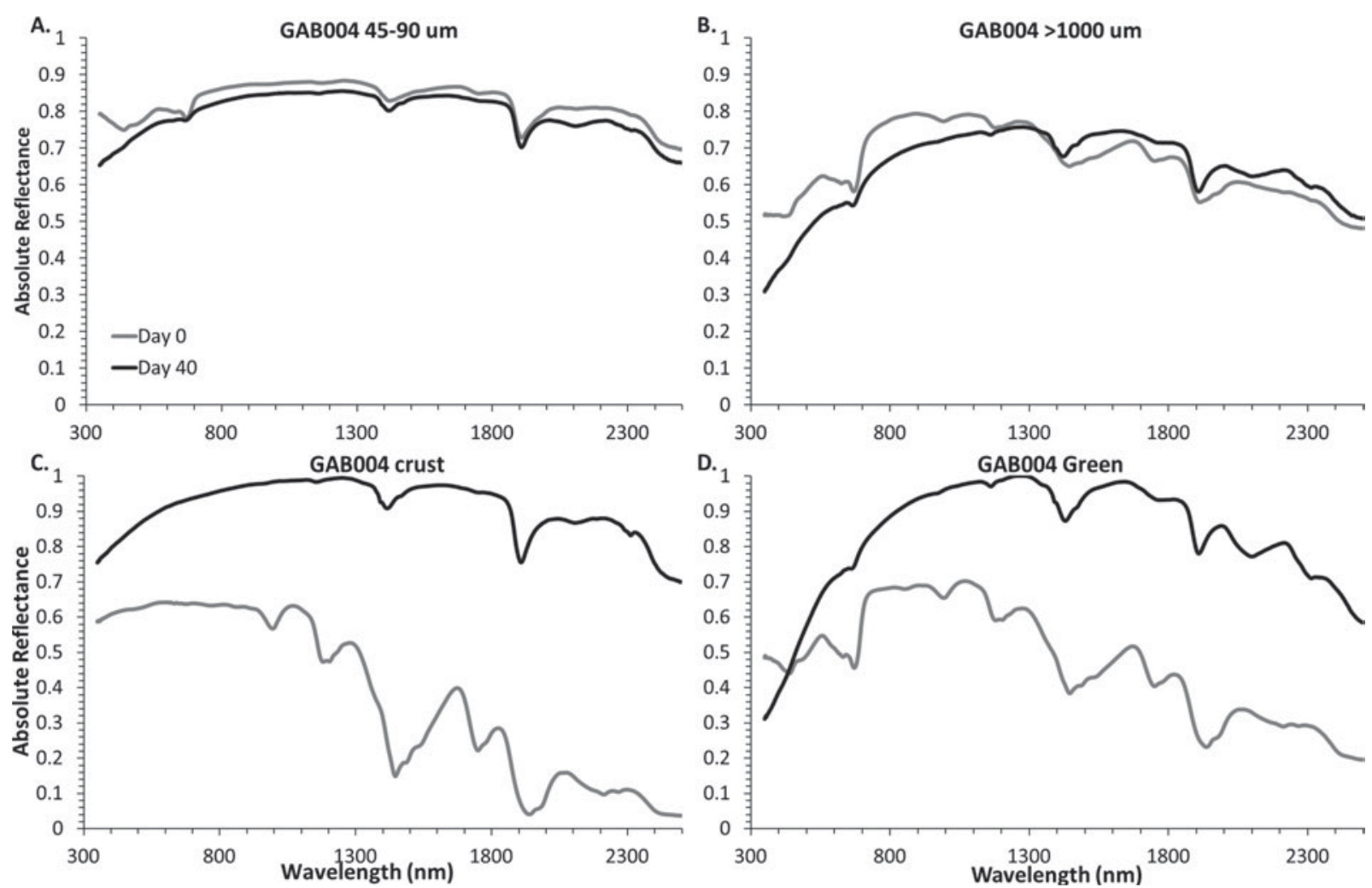

Fig. 8. Reflectance spectra of gypsum endolith sample GAB004 both crushed green communities (A,B) and whole rock gypsum crust and endolith community (C,D) prior to and following 40 days of desiccation under Mars-like conditions. See Fig. 4 for sample photos. 
Table 3. Chlorophyll band depth percentage of each sample prior to and after exposure to Mars-like conditions

\begin{tabular}{|c|c|c|c|c|}
\hline Sample & Description & $\begin{array}{l}\text { Depth } \\
\% \text { (fresh) }\end{array}$ & $\begin{array}{l}\text { Depth \% } \\
\text { (desiccated) }\end{array}$ & $\begin{array}{l}\text { Depth \% } \\
\text { decrease }\end{array}$ \\
\hline \multicolumn{5}{|c|}{ EAST GERMAN CREEK } \\
\hline EGC 20111 & Outwash sediment & 28.7 & 2.8 & 90.4 \\
\hline 2 & Outwash sediment & 5.0 & 0.5 & 91.0 \\
\hline 3 & Outwash sediment & 8.4 & 1.9 & 77.3 \\
\hline 4 & Outwash sediment & 11.7 & 4.3 & 63.7 \\
\hline 5 & Outwash sediment & $2.55 \mathrm{E}-13$ & $7.77 \mathrm{E}-14$ & - \\
\hline 6 & Outwash sediment & $4.44 \mathrm{E}-13$ & 0.2 & - \\
\hline 7 & Outwash sediment & 6.1 & 2.6 & 56.9 \\
\hline 8 & Outwash sediment & $-4.44 \mathrm{E}-14$ & $7.77 \mathrm{E}-14$ & - \\
\hline 9 & Outwash sediment & 6.3 & 0.2 & 97.6 \\
\hline EGC $2010 \mathrm{BB}$ & Black brains & 13.3 & 11.2 & 16.2 \\
\hline WB & White brains & 30.8 & 2.6 & 91.7 \\
\hline 001 & Mound Sediments & 19.5 & $1.89 \mathrm{E}-13$ & 100 \\
\hline 001 & Mound Algae & 53.8 & 4.1 & 92.4 \\
\hline 005 & Outwash mats & 8.1 & 5.8 & 27.9 \\
\hline 006 & Outwash mats & 16.3 & 4.1 & 74.6 \\
\hline 008 & Outwash mats & 41.7 & 25.3 & 39.2 \\
\hline 010 & Outwash mats & 52.8 & 1.9 & 96.3 \\
\hline 012 & Outwash Mats & 49.0 & 21.8 & 55.5 \\
\hline \multicolumn{5}{|c|}{ LAKE ST. MARTIN } \\
\hline GAB004 $<45 \mu \mathrm{m}$ & Crushed & 4.5 & 1.5 & 66.6 \\
\hline $45-90 \mu \mathrm{m}$ & Crushed & 4.5 & 1.6 & 64.3 \\
\hline $90-250 \mu \mathrm{m}$ & Crushed & 4.1 & 1.5 & 63.7 \\
\hline $250-500 \mu \mathrm{m}$ & Crushed & 5.9 & 2.1 & 64.8 \\
\hline $500-1000 \mu \mathrm{m}$ & Crushed & 4.8 & 1.7 & 64.9 \\
\hline$>1000 \mu \mathrm{m}$ & Crushed & 11.4 & 5.3 & 53.8 \\
\hline GYP611 blue & Whole rock & 3.3 & 0.1 & 95.8 \\
\hline Green & Whole rock & 8.8 & 0.0 & 99.9 \\
\hline White & Whole rock & 0.2 & 0.1 & 57.2 \\
\hline White & Whole rock & 0.1 & 0.02 & 86.3 \\
\hline Green & Whole rock & 35.9 & 7.00 & 80.6 \\
\hline GAB004 white & Whole rock & 0.4 & 0.03 & 93.3 \\
\hline Orange & Whole rock & 18.3 & 3.2 & 82.4 \\
\hline Green & Whole rock & 19.4 & 5.5 & 71.5 \\
\hline PM white & Whole rock & 0.2 & $3.11 \mathrm{E}-13$ & 100.00 \\
\hline Orange & Whole rock & 11.8 & 5.4 & 54.4 \\
\hline Green & Whole rock & 31.9 & 11.2 & 65.1 \\
\hline
\end{tabular}

thermoelectrically cooled and temperature controlled. Band depths in the $670 \mathrm{~nm}$ region have been calculated using equation (32) of Clark \& Roush (1984), with the continuum placed at 640 and $710 \mathrm{~nm}$ for all calculations.

All X-ray diffraction (XRD) patterns were acquired at the University of Manitoba with continuous scan data from $10-70^{\circ} 2-\theta$ on a Philips PW1710 automated powder diffractometer using a PW1050 Bragg-Brentano goniometer equipped with incident- and diffracted beam Soller slits, $1.0^{\circ}$ divergence and anti-scatter slits, a $0.2 \mathrm{~mm}$ receiving slit and a curved graphite diffracted-beam monochromator. The normal focus $\mathrm{Cu}$ X-ray tube was operated at $40 \mathrm{kV}$ and $40 \mathrm{~mA}$ using a takeoff angle of $6^{\circ}$. Quantitative analysis was carried out using TOPAS (Bruker AXS Inc.), a PC-based program that performs Rietveld refinement of XRD patterns.

\section{Deconvolution to Pancam and Mastcam spectra}

To simulate Pancam observations of these materials on the Martian surface, the high-resolution laboratory spectra was multiplied by the Solar spectrum, weighted the resulting radiance spectra by the Pancam spectral bands (Table 1; Bell et al. 2003), and divided the radiance value at each band by the Solar spectrum weighted by that band. This method provides 11 wavelength spectra that can be used for direct comparison with Pancam relative reflectance values (Bell et al. 2006). The same procedure was performed for the Mastcam 'science filter' and Bayer filter spectral bands (Table 1; Ghaemi 2009; Malin et al. 2010; Bell et al. 2012) in order to address the implications of our results for observations by the MSL rover.

\section{Results - spectral changes}

\section{Lake St. Martin gypsum endoliths}

The spectra of the endolith samples are dominated by characteristic features of gypsum which can be observed by comparing the laboratory reference pure gypsum standard (Fig. 6) to that of the endolithic communities (Figs. 7 and 8). Pure gypsum is characterized by high overall reflectance and 

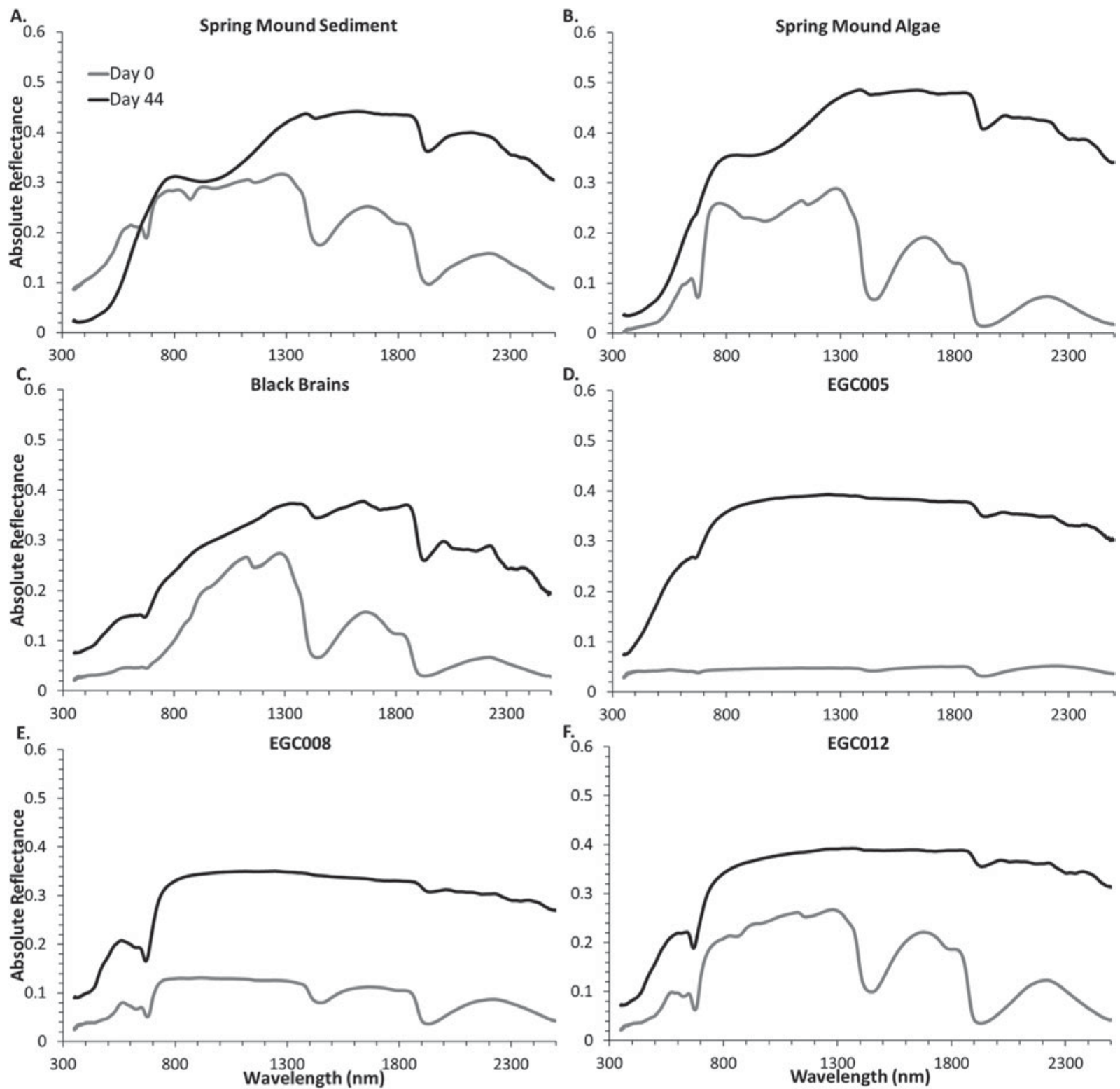

Fig. 9. Reflectance spectra of the 2010 East German Creek samples prior to and following 44 days of desiccation under Mars-like conditions.

complex overtone and combination features in the UV/VIS region (Table 2), in particular prominent distinctive $\mathrm{O}-\mathrm{H}$ stretching and $\mathrm{H}-\mathrm{O}-\mathrm{H}$ bending overtone features at $\sim 1400$ and $1900 \mathrm{~nm}$ (Cloutis et al. 2006). The presence of the endolithic community is evidenced by a decrease in absolute reflectance below $800 \mathrm{~nm}$ and a prominent absorption feature at $\sim 670 \mathrm{~nm}$, as well as weaker features below that which are attributed to the green photosynthetic pigment chlorophyll and orange photo protective pigments such as carotenoids (Fig. 4) (Richardson 1995; Quesada et al. 1999). Band depths of the $\sim 670 \mathrm{~nm}$ feature (Table 3) ranged from 4.1 to $35.9 \%$ in endolith bearing samples. Interestingly, a band not visible in qualitative data analysis was detected in the outer surface of the gypsum boulder where no endoliths were visually present, although its depth was considerably smaller than the endolithbearing gypsum $(<0.5 \%)$. With exposure to the UV, anoxia, low-pressure and desiccating conditions, there was little change in the spectra of the samples. All of the major spectral features of the day 0 spectra remained even after 40 days of incubation. The largest changes in the spectra were associated with the dehydration of the gypsum, i.e., with the weakening of the distinctive water features at 1400 and $1900 \mathrm{~nm}$. The features below $800 \mathrm{~nm}$ that are associated with the endolithic communities remained after 40 days. However, they became considerably weaker, with decreases in band depth ranging from 53.8 to $99.9 \%$. This pattern was seen both in the whole rock samples as well as the crushed samples. There is a correlation seen in whole rock samples related to whether the endoliths were directly exposed to the UV source (GYP611) as opposed to not directly exposed due to a gypsum covering (GYP612,PM) (Fig. 4). The depth of the chlorophyll absorption feature in Gyp611 decreases by $99.9 \%$ as opposed to 

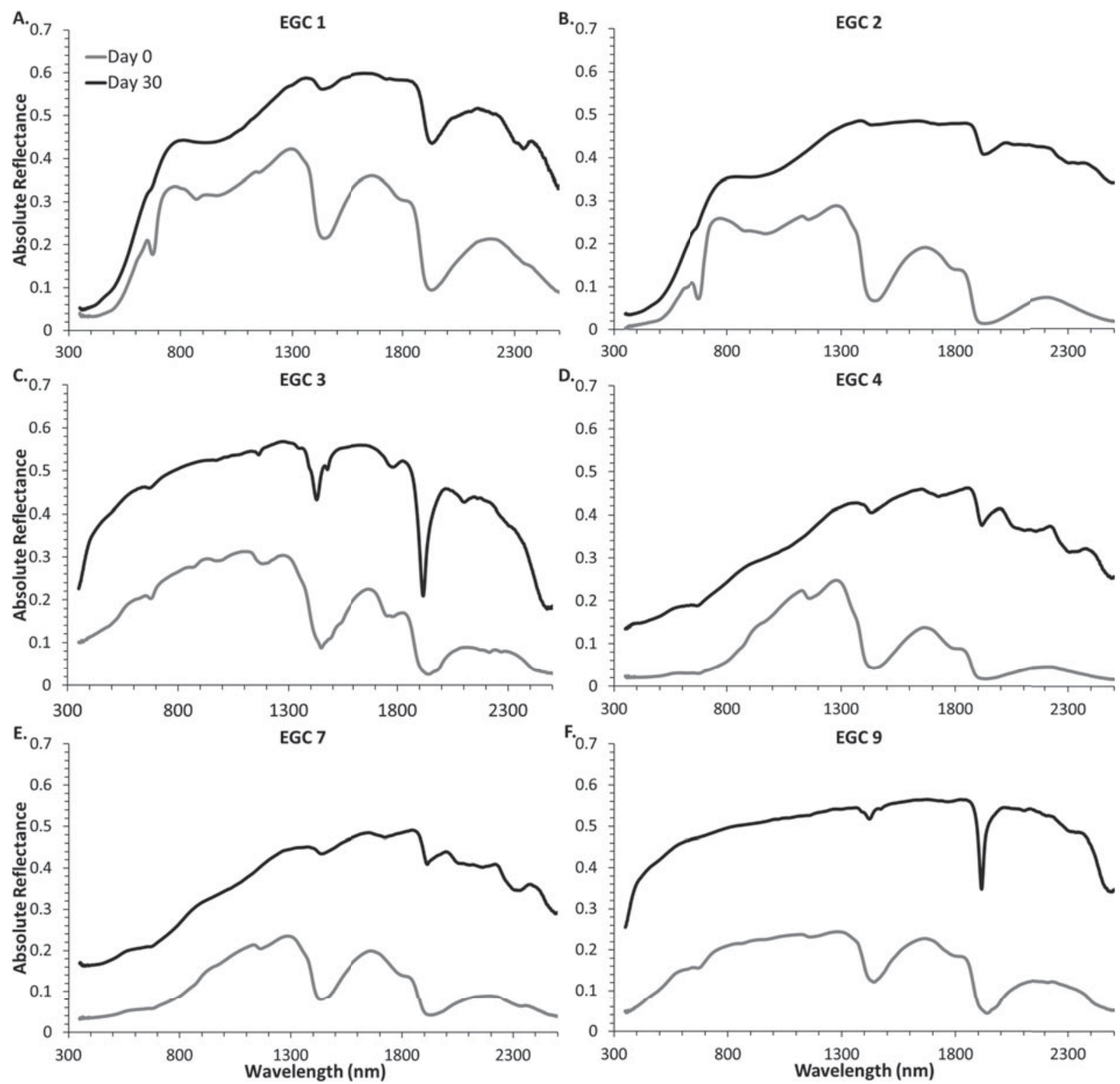

Fig. 10. Reflectance spectra of the 2011 East German Creek samples prior to and following 30 days of desiccation under Mars-like conditions. See Fig. 5 for sample photos.

$65.1 \%$ in GYPPM, which was not directly exposed (Fig. 4). No correlation was found in the preservation of band depth in the orange versus green endoliths as it varied between samples.

\section{East German Creek 2010}

Main spring ('big cauldron'): sediments and algae

Prior to desiccation, the spectra of both the sediment and algae have low overall reflectance due to the strong $\mathrm{O}-\mathrm{H}$ stretching and $\mathrm{H}-\mathrm{O}-\mathrm{H}$ bending overtones at 1450 and $1900 \mathrm{~nm}$ (Fig. 9). There is a strong drop in reflectance shortward of $\sim 800 \mathrm{~nm}$ with a chlorophyll absorption feature at $\sim 670 \mathrm{~nm}$. This feature is most prominent in the algae sample prior to desiccation. After desiccation, the $\mathrm{OH} / \mathrm{H}_{2} \mathrm{O}$ bands are reduced in intensity, and increases in absolute reflectance are observed in both samples. The chlorophyll absorption feature is essentially absent in the desiccated sediment spectra, with total absence or only a small shoulder apparent in the algal spectra. This corresponds to a loss in band depth of 100 and 92.4\%, respectively. However, the decrease in overall reflectance below $\sim 750 \mathrm{~nm}$ remains, which corresponds to the 'red edge' of plant spectra and is considered to be a potential biosignature in exoplanet research (Seager et al. 2005). After desiccation, a very weak carbonate band can be observed at $2350 \mathrm{~nm}$.

Outwash plains: 'brains' and mats

The reflectance spectra of the outflow plain 'brains' are dominated by strong $\mathrm{O}-\mathrm{H}$ stretching and $\mathrm{H}-\mathrm{O}-\mathrm{H}$ bending overtones at 1450 and $1900 \mathrm{~nm}$, which are intense enough to cause an overall decrease in reflectance longward of $\sim 1300 \mathrm{~nm}$ (Fig. 9). The chlorophyll absorption feature at $\sim 670 \mathrm{~nm}$ can 


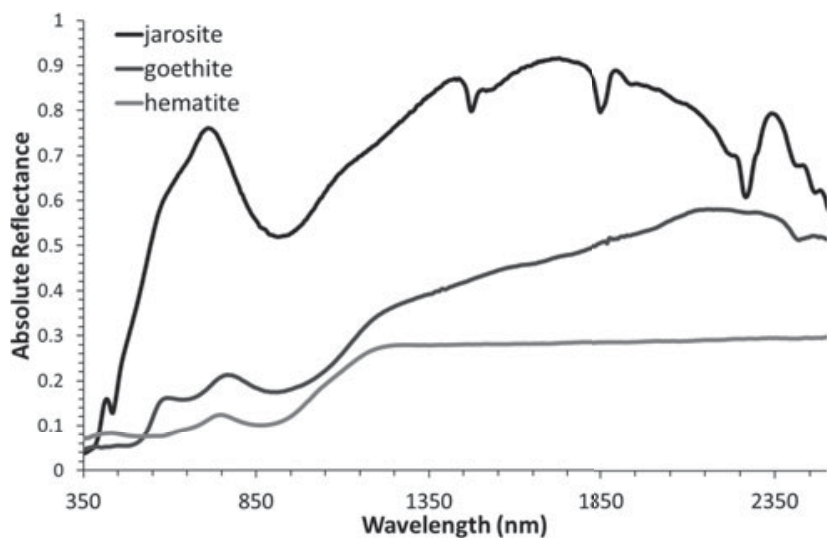

Fig. 11. RELAB reflectance spectra from the HOSERLab data base of pure iron bearing minerals with a characteristic drop in reflectance below $\sim 1000 \mathrm{~nm}$ similar to the chlorophyll 'red edge'.

be observed in the undesiccated sample spectrum, and is preserved better than the spring mound spectra following desiccation, with band depth decreases ranging from 16.2 to $91.7 \%$ with the black brains showing the smallest decrease in band depth among all of the samples. Post desiccation, the $\mathrm{OH} / \mathrm{H}_{2} \mathrm{O}$ bands were still present but were much less pronounced. As well, an absorption feature indicative of carbonates became more apparent at $2350 \mathrm{~nm}$ as was the case with the main spring samples. In contrast to the spring samples, a shallow absorption band can be observed post desiccation at $2100 \mathrm{~nm}$, indicative of the presence of gypsum, and a small absorption at $1750 \mathrm{~nm}$ may indicate the presence of organic molecules (C-H stretching overtones).

The mats collected from the plains along the main outflow channel follow the same general trends as the 'brains' samples upon desiccation. Interestingly, the samples from EGC5 and had a shallow 'red edge' prior to desiccation and which became steeper over the 44 days (Fig. 9). While EGC005 had only a small $670 \mathrm{~nm}$ band depth of $8.1 \%$, it showed the best preservation with a loss of only $27.9 \%$ of its initial value (Table 3). The overall reflectance of the spectra for all samples increased as the $\mathrm{O}-\mathrm{H}$ stretching and $\mathrm{H}-\mathrm{O}-\mathrm{H}$ bending overtones became weaker. The chlorophyll absorption feature at $670 \mathrm{~nm}$ remained even after desiccation in all the sample spectra; this is especially prominent in samples EGC008, and EGC012 with decreases of 39.2 and 55.4\%, respectively. This correlates with visible mineral precipitation on the surface of the samples observed during desiccation. As well, the $\mathrm{C}-\mathrm{O}$ stretching feature indicative of carbonates at $2350 \mathrm{~nm}$ is evident in all the sample spectra.

\section{East German Creek 2011}

Outwash plain sediments

The outwash plain sediment spectra are dominated by the strong $\mathrm{O}-\mathrm{H}$ stretching and $\mathrm{H}-\mathrm{O}-\mathrm{H}$ bending overtones in the 1400 and $1900 \mathrm{~nm}$ regions. Although there is a pervasive surficial staining by Fe-oxyhydroxides, these phases are volumetrically insignificant. The $\mathrm{Fe}^{3+}-\mathrm{O}$ charge transfer
Table 4. Continuum removed band depth for the $670 \mathrm{~nm}$ region for jarosite, hematite, and goethite

\begin{tabular}{llll}
\hline Sample & Depth $\%$ & Depth \% Pancam & Depth \% Mastcam \\
\hline Jarosite & 0.03 & 0 & 0 \\
Hematite & 2.6 & 4.8 & 5.8 \\
Goethite & 3.1 & 11.8 & 10.3 \\
\hline
\end{tabular}

absorption band dramatically decreases reflectance below $\sim 800 \mathrm{~nm}$ (Fig. 10). In the fresh samples, the chlorophyll $a$ absorption band is very evident in samples EGC1, EGC3 and, EGC9, and is also present in samples EGC2, EGC4 and EGC7 with band depths ranging from 5 to $28.7 \%$.

After exposure to Mars-like conditions, the spectra undergo significant increases in absolute reflectance due to halite and gypsum precipitation (determined by XRD) and decrease in $\mathrm{OH} / \mathrm{H}_{2} \mathrm{O}$ band depths due to the desiccating conditions of the environment chamber. This precipitation can be visually observed in the post-desiccation samples (Fig. 5). In all samples, the characteristic carbonate band near $2300 \mathrm{~nm}$ becomes very apparent. The chlorophyll $a$ spectral signature remains relatively strong in samples EGC3, EGC4 and EGC7, with decreases of 77.3, 63.7 and $56.9 \%$ from initial band depth, respectively. A greater decrease in band depth is observed in samples EGC1, EGC2 and EGC 9 (90.4, 91.0 and $97.6 \%$, respectively) with only a weak shoulder remaining.

\section{Iron-bearing minerals}

A reflectance decline, usually at shorter wavelengths, can also be attributable to charge transfers in minerals, particularly $\mathrm{Fe}^{3+}$-bearing oxyhydroxides such as hematite, goethite and jarosite (Fig. 11) (Crowley et al. 2003). This red edge occurs at a different position than the chlorophyll red edge and lacks the smaller-scale absorption features of the chlorophyll feature. However, band depth calculation from high-resolution laboratory spectra show that the $670 \mathrm{~nm}$ feature in hematite, goethite or jarosite has band depths of 2.6, 3.0 and $0.03 \%$ respectively (Table 4). These values make the mineral spectra distinguishable from pre-desiccation chlorophyll spectra but this does not apply to many of the post-desiccation chlorophyll band depth values with the exception of the least-affected samples (Table 3). The positions of these crystal field transition bands vary depending on the mineral in question, but fall between 430-480, 650-670 and 910-940 nm (Sherman \& Waite 1985; Crowley et al. 2003). Owing to the presence of multiple features, $\mathrm{Fe}$-oxyhydroxides can be distinguished from chlorophyll bands by the presence of the $\sim 900 \mathrm{~nm}$ absorption band, which is considerably deeper than the feature near $670 \mathrm{~nm}$.

\section{Deconvolution of data to Pancam and Mastcam resolution}

When deconvolved to Pancam and Mastcam bands, the spectra lose their fine details, however it is apparent that some relevant spectral features can still be discerned (Figs. 12-14). While not preserved post-desiccation, the $\mathrm{O}-\mathrm{H}$ 

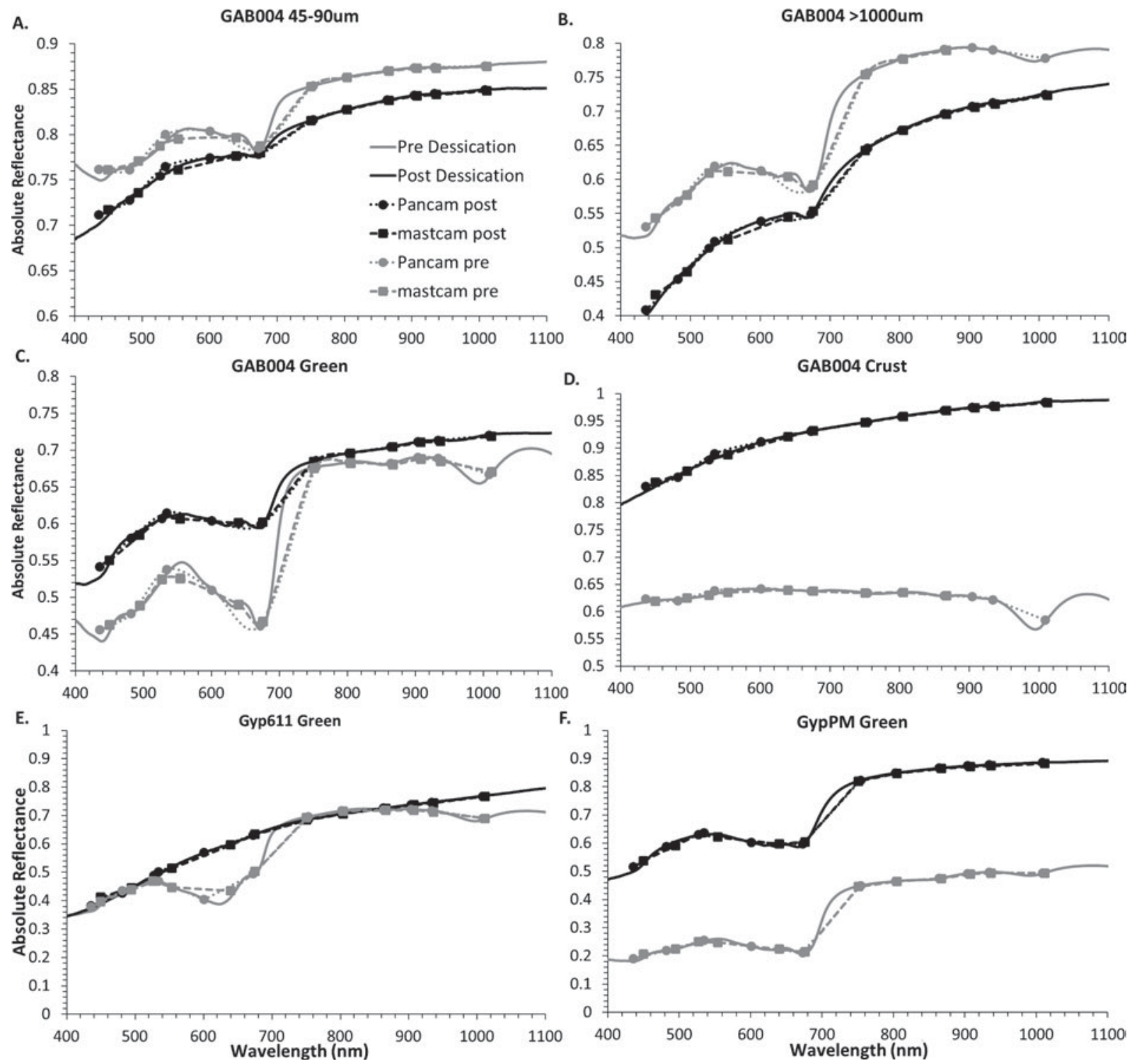

Fig. 12. Reflectance spectra of gypsum endolith samples pre and post desiccation for the 400-100 nm region convolved to Pancam and Mastcam band passes. Differences in chlorophyll preservation are apparent when comparing grain size (A,B), endolithic community vs. pure gypsum (C,D) and whether that community is directly exposed to UV vs. mineral shielded (E,F).

hydration feature at $\sim 1100 \mathrm{~nm}$ can be inferred by the drop in reflectance observed in the 1009 and $1012 \mathrm{~nm}$ filters of Pancam and Mastcam, respectively. As well, the drop in reflectance below $\sim 800 \mathrm{~nm}$ is apparent and preserved in all of the deconvolved spectral. The preservation of these features follows the same patterns in the Pancam and Mastcam data as is observed in the endolith laboratory data, with the chlorophyll feature better preserved in samples that are less exposed to the UV source (Fig. 12(c) and (d)). For the EGC samples, the chlorophyll feature is much more subdued in the deconvolved spectra from the outwash plain sediment samples (Fig. 13). It should be noted that the $\sim 670 \mathrm{~nm}$ chlorophyll feature is observed using both Mastcam than Pancam data. This is primarily attributed to the use of the Mastcam Bayer Filters in addition to the Science Filters, which adds filters at 554 and $640 \mathrm{~nm}$, and the 601 Pancam filter that allows one to discern the increase in reflectance or 'chlorophyll bump' that precedes the chlorophyll absorption feature, which is not observed in mineral spectra with a similar red edge and $\sim 670 \mathrm{~nm}$ feature (Fig. 14). This is supported by band depth calculations (Tables 5 and 6), where the Pancam and Mastcam band depths correlate well with the laboratory data (Table 3). However, it should be noted that evidence of the chlorophyll feature in the Mastcam spectra without the addition of the Bayer filters is only detectable in those samples with the greatest degree of preservation and a wider absorption feature.

When the spectra of iron oxyhydroxide minerals are deconvolved to Pancam and Mastcam (Fig. 14), it is possible to distinguish between mineral spectra and chlorophyllbearing rocks qualitatively despite their coarser spectral resolution. The distinct drop in reflectance associated with 

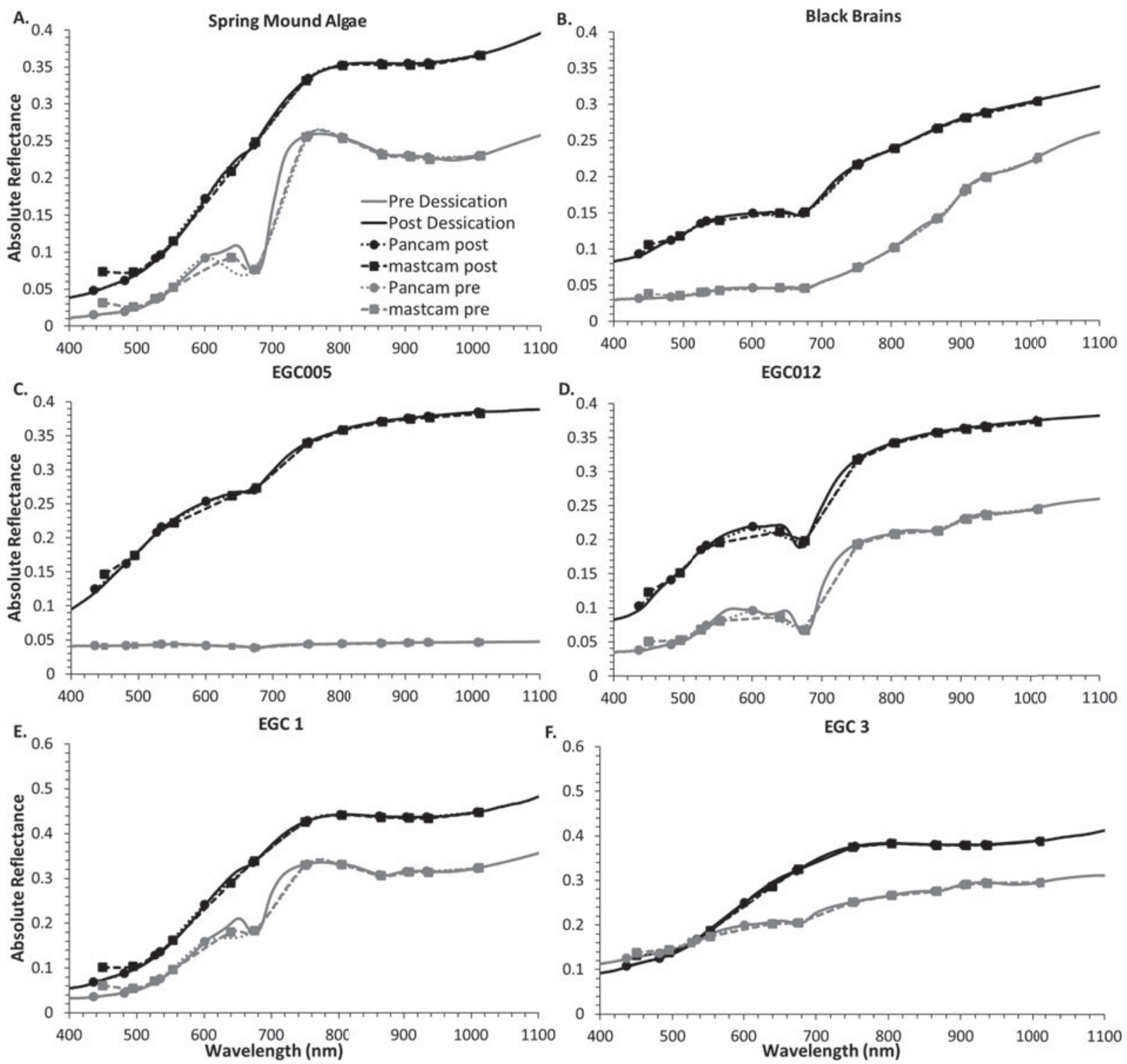

Fig. 13. Reflectance spectra of EGC 2010 (A-D) and 2011 (E,F) spring and outwash sediment samples pre and post desiccation for the 400$1000 \mathrm{~nm}$ region convolved to Pancam and Mastcam band passes.

the red edge of chlorophyll at $\sim 750 \mathrm{~nm}$, as well as the $\sim 670 \mathrm{~nm}$ chlorophyll feature are distinct to the endolith and outwash mat spectra. The mineral spectra show a drop in reflectance above $\sim 800 \mathrm{~nm}$ due to their strong $\mathrm{Fe}^{3+}$ feature near $900 \mathrm{~nm}$, which is not observed in the EGC and Gypsumville samples. However, when only the $670 \mathrm{~nm}$ band depth is considered, there is some ambiguity, as the $670 \mathrm{~nm}$ band depth for Pancam spectra ranges from $0 \%$ for jarosite to $4.8 \%$ for hematite and $11.8 \%$ for goethite (Table 4 ), which is comparable with the values for the chlorophyll feature in some of the desiccated sample spectra (Tables 5 and 6 ).

\section{Discussion}

While the reflectance spectral features of chlorophyll are readily eroded by ionizing radiation (Dartnell et al. 2011), we have shown that the red edge and $670 \mathrm{~nm}$ feature can be preserved in the presence of evaporitic mineral assemblages under Martian surface conditions. While our experiments were run for up to 44 days, the samples were exposed to UV irradiation equivalent to $\sim 300$ years at present Mars surface conditions. This is relevant, as preservation of these spectral features is dependent on the degradation rate of the chemical structure of the chlorophyll molecule, in particular its pi-bonded porphyrin ring, which, under present Mars conditions is primarily affected by UV irradiation (Cockell et al. 2000; Dartnell et al. 2007). However, this UV flux has been shown to be attenuated by minerals such as sulphates and carbonates (section 3.2), which absorb wavelengths that degrade biomolecules, allowing for organisms to survive under harsh conditions, and for biomolecules to be preserved (Rothschild 1990). 

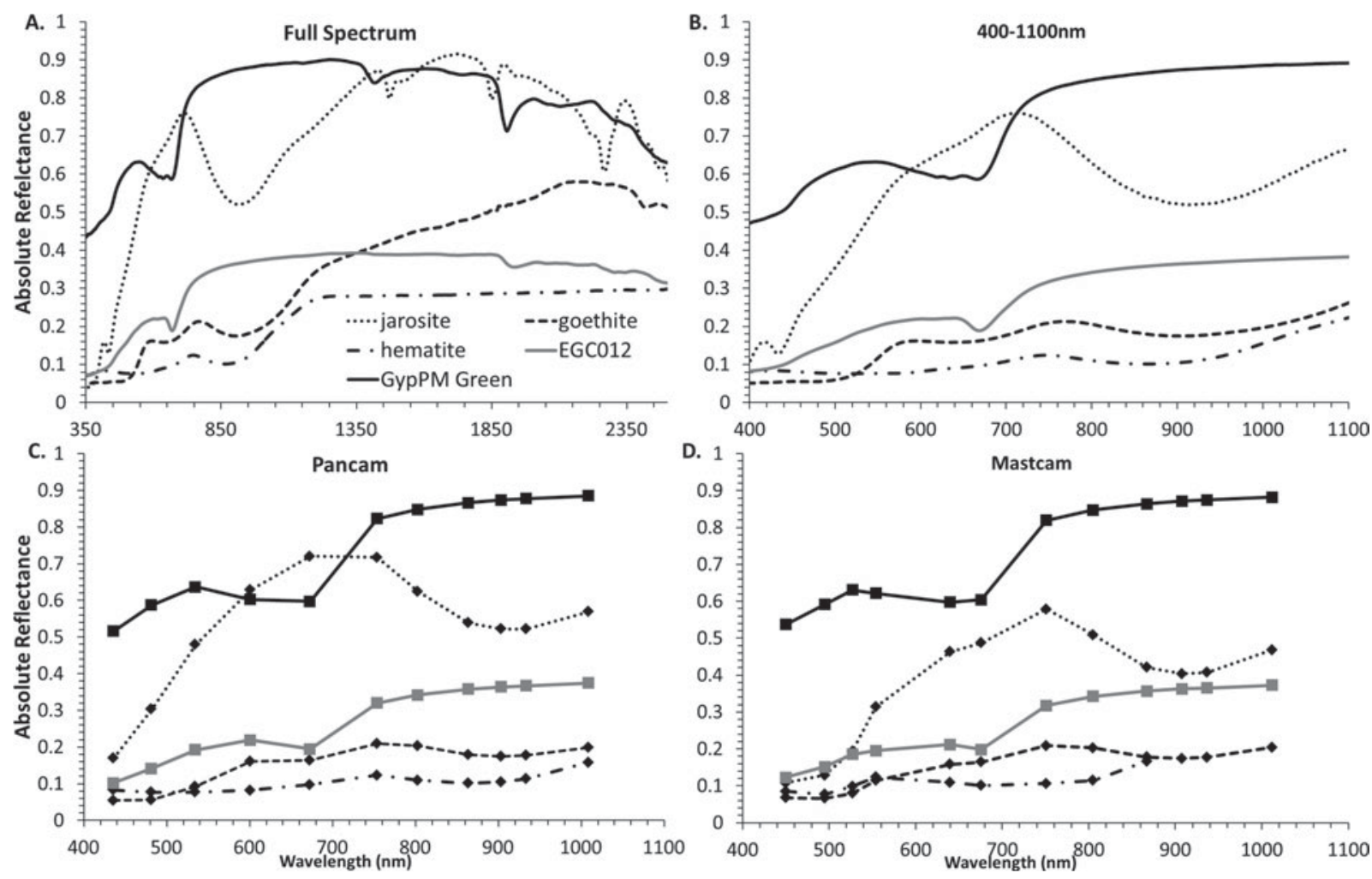

Fig. 14. A. The full reflectance spectrum of the analogue site samples post desiccation compared to minerals with similar spectral features. B. 400-1100 nm (rover) range reflectance spectra of the same samples C/D. Post desiccation samples and reference spectra deconvolved to: C. Pancam, D. Mastcam.

Hypersaline spring and evaporite deposits that are rich in hydrated sulphates, salts and carbonates are considered to be among the highest priority targets for the survival of microbial life on Mars, and preservation and hence, detection of biomarkers (Rothschild 1990; Grasby et al. 2003; Manicelli et al. 2004; Grasby \& Londry 2007; Aubrey et al. 2006; Summons et al. 2011; Schopf et al. 2012). While such terrains have been detected on Mars (Langevin et al. 2005; Allen \& Oehler 2008; Ehlmann \& Mustard 2012; Squyres et al. 2012), it is imperative to be able to select specific targets for higher resolution analysis within such areas. Based on our data, we can make some suggestions for such targets. We observe correlations between the proximity of samples to geomorphological features, mineral assemblages, and the preservation of the chlorophyll spectral feature.

In the EGC outwash plain sediments, there is a general geographic control associated with chlorophyll $a$ spectral feature; samples 1-4 were taken very close to the main spring mound, and sample 7 was taken from an elevated portion of the outwash plain that is likely an extinct mound. The chlorophyll feature is present in a greater proportion of samples closer to the mound. However, while samples taken directly from the spring vent (algae and sediment) lose their chlorophyll feature, they retain a prominent red edge at $\sim 800$; as noted, this is longward of known minerals with an absorption edge in this region (Fig. 13).

Our data strongly suggest that the most significant control on spectral biosignature preservation is mineralogy, as a relationship between mineralogy and biosignature preservation is observed in all samples. All of the EGC 2011 samples, with the exception of samples 6 and 8, developed a white precipitate upon desiccation, composed of gypsum and/or halite and calcite (Fig. 5). Samples with a precipitate identified as gypsum by XRD $(2,3,4,7,9)$, have a better preserved chlorophyll spectral signature. Samples with a larger ratio of gypsum to halite have a deeper chlorophyll band upon desiccation than those with smaller gypsum to halite ratios. This also applies to samples from outwash mats 8 and 12 from EGC 2010 which had observable surficial mineral precipitation and the strongest preservation of the chlorophyll signature. Mineralogy of the precipitate was determined by XRD to be primarily calcite with minor gypsum and halite, which is expected that spring fluids are highly saline and have travelled through a carbonate reef system. However, this also suggests that the pervasive calcite may also be playing a role in preservation of the chlorophyll feature, likely by UV shielding. In addition, it has been shown by Cockell et al. (2008) that even $1 \mathrm{~mm}$ of mineral grains is sufficient to prevent UV damage to endolithic communities (which is in an agreement with our $2 \mathrm{~mm}$ gypsum slab UV transmission results). The potential role of carbonate in the preservation of biosignatures is of particular interest, as like gypsum, it is a spectrally detectable mineral. While halite may play a role in preservation, it is spectrally undetectable at the wavelengths used.

The association of gypsum with chlorophyll preservation is further strengthened by the fact that the preservation of the 
Table 5. Pancam continuum removed band depth of the 601-673-754 nm 'kink'

\begin{tabular}{|c|c|c|c|c|}
\hline Sample & Description & Depth \% (fresh) & Depth \% (desiccated) & Depth \% decrease \\
\hline \multicolumn{5}{|c|}{ EAST GERMAN CREEK } \\
\hline EGC 20111 & Outwash sediment & 25.5 & 0 & 100 \\
\hline 2 & Outwash sediment & 0.1 & 0 & 100 \\
\hline 3 & Outwash sediment & 9.6 & 2.7 & 71.9 \\
\hline 4 & Outwash sediment & 20.5 & 7.8 & 62.0 \\
\hline 5 & Outwash sediment & 0 & 0 & - \\
\hline 6 & Outwash sediment & 0 & 0.8 & - \\
\hline 7 & Outwash sediment & 11.8 & 6.0 & 49.2 \\
\hline 8 & Outwash sediment & 0 & 0 & - \\
\hline 9 & Outwash sediment & 10.6 & 0.4 & 96.2 \\
\hline EGC 2010 BB & Black brains & 24.6 & 18.5 & 24.8 \\
\hline WB & White brains & 33.8 & 2.8 & 91.7 \\
\hline 001 & Mound sediments & 21.8 & 0 & 100 \\
\hline 001 & Mound algae & 56.4 & 3.6 & 93.6 \\
\hline 005 & Outwash mats & 9.6 & 8.9 & 7.3 \\
\hline 006 & Outwash mats & 17.2 & 5.3 & 69.2 \\
\hline 008 & Outwash mats & 46.0 & 33.1 & 28.0 \\
\hline 010 & Outwash mats & 60.1 & 3.5 & 94.2 \\
\hline 012 & Outwash mats & 53.9 & 27.8 & 48.4 \\
\hline \multicolumn{5}{|c|}{ LAKE ST. MARTIN } \\
\hline GAB004 $<45 \mu \mathrm{m}$ & Crushed & 5.3 & 1.9 & 64.1 \\
\hline $45-90 \mu \mathrm{m}$ & Crushed & 5.3 & 2.2 & 58.5 \\
\hline $90-250 \mu \mathrm{m}$ & Crushed & 4.8 & 2.0 & 58.3 \\
\hline $250-500 \mu \mathrm{m}$ & Crushed & 6.8 & 2.7 & 60.3 \\
\hline $500-1000 \mu \mathrm{m}$ & Crushed & 5.4 & 2.0 & 63.0 \\
\hline$>1000 \mu \mathrm{m}$ & Crushed & 14.0 & 7.2 & 48.6 \\
\hline GYP611 blue & Whole rock & 2.0 & 0 & 100 \\
\hline Green & Whole rock & 10.0 & 0 & 100 \\
\hline White & Whole rock & 0 & 0 & - \\
\hline White & Whole rock & 0 & 0 & - \\
\hline Green & Whole rock & 40.4 & 9.5 & 76.5 \\
\hline GAB004 white & Whole rock & 0.1 & 0 & 100 \\
\hline Orange & Whole rock & 19.3 & 4.2 & 78.2 \\
\hline Green & Whole rock & 22.0 & 7.1 & 67.7 \\
\hline PM white & Whole rock & 0.3 & 0 & 100 \\
\hline Orange & Whole rock & 13.3 & 7.0 & 47.4 \\
\hline Green & Whole rock & 38.0 & 16.3 & 57.1 \\
\hline
\end{tabular}

chlorophyll spectral signature in the endoliths at the LSM crater is much stronger than in the EGC samples. In the LSM samples it is apparent that in order for the chlorophyll spectral signature and thus, molecule, to be preserved, it must not be exposed directly to UV irradiation but must be shielded by a layer of gypsum. This further substantiates the idea of sulphates, particularly gypsum, as an effective substrate for biosignature preservation. However, it also presents an impediment to the detection of this biosignature, as order to detect the chlorophyll you must have access to a previously unexposed sample, either by breaking it open or grinding away the protective gypsum layer. Regardless, this holds great astrobiological relevance given the detection of gypsum in veins at Endeavour crater (Squyres et al. 2012). The gypsum at Endeavour is interpreted as having precipitated from lowtemperature fluids and has been proposed to have led temporarily to habitable conditions (Squyres et al. 2012). Should the habitability of this fluid system have been taken advantage of by early life forms (if present on Mars), sulphates have been shown to preserve organic molecules on geologically relevant timescales (Aubrey et al. 2006; Schopf et al. 2012). Additionally, endolithic communities such as those found in the LSM gypsum are ubiquitous in gypsum and other evaporitic minerals deposits on Earth, even in the most extreme settings (Friedmann 1982; Cockell et al. 2002; Hughes \& Lawley 2003; Stivaletta et al. 2010).

While the high-resolution nature of laboratory spectral data allows for the detection of the chlorophyll feature even when it is not strongly preserved ( $>75 \%$ loss in band depth), this is not the case for lower-resolution spectral data. When analysing Pancam and Mastcam data, strong preservation of the $670 \mathrm{~nm}$ chlorophyll feature is required for detection, while the red edge remains readily detectable. Complications arise for chlorophyll absorption band detection with the presence of $\mathrm{Fe}^{3+}$-rich minerals, which in the case of Mars, dominate many surface spectra. The UV/VIS spectra of these minerals is dominated by crystal field transitions and a fall off towards the UV associated with paired excitations of magnetically coupled $\mathrm{Fe}^{3+}$ cations (Sherman \& Waite 1985). The positions of these crystal field transition bands vary depending on the mineral in question, 
Table 6. Mastcam continuum removed depth of the 640-552 676-751 nm 'kink'

\begin{tabular}{|c|c|c|c|c|}
\hline Sample & Description & Depth \% (fresh) & Depth \% (desiccated) & Depth $\%$ decrease \\
\hline \multicolumn{5}{|c|}{ EAST GERMAN CREEK } \\
\hline EGC 20111 & Outwash sediment & 27.2 & 5.1 & 81.3 \\
\hline 2 & Outwash sediment & 5.8 & 1.6 & 72.4 \\
\hline 3 & Outwash sediment & 9.9 & 2.8 & 71.7 \\
\hline 4 & Outwash sediment & 19.4 & 7.5 & 61.3 \\
\hline 5 & Outwash sediment & 1.3 & 0.1 & 92.3 \\
\hline 8 & Outwash sediment & 1.1 & 3.3 & - \\
\hline 7 & Outwash sediment & 11.9 & 5.9 & 50.4 \\
\hline 8 & Outwash sediment & 1.8 & 1.1 & 38.9 \\
\hline 9 & Outwash sediment & 10.8 & 0.7 & 93.5 \\
\hline EGC2010 BB & Black brains & 23.4 & 17.7 & 26.5 \\
\hline WB & White brains & 31.6 & 3.4 & 89.6 \\
\hline 001 & Mound sediments & 20.1 & 2.9 & 85.6 \\
\hline 001 & Mound algae & 55.9 & 7.9 & 85.9 \\
\hline 005 & Outwash mats & 8.2 & 8.9 & - \\
\hline 006 & Outwash mats & 15.6 & 5.8 & 62.8 \\
\hline 008 & Outwash mats & 44.0 & 29.8 & 32.3 \\
\hline 010 & Outwash mats & 58.7 & 4.5 & 92.3 \\
\hline 012 & Outwash mats & 51.9 & 25.0 & 51.8 \\
\hline \multicolumn{5}{|c|}{ LAKE ST. MARTIN } \\
\hline GAB004 <45 $\mu \mathrm{m}$ & Crushed & 4.5 & 1.8 & 60.0 \\
\hline $45-90 \mu \mathrm{m}$ & Crushed & 4.5 & 2.0 & 55.6 \\
\hline $90-250 \mu \mathrm{m}$ & Crushed & 4.3 & 1.9 & 55.8 \\
\hline $250-500 \mu \mathrm{m}$ & Crushed & 6.2 & 2.5 & 59.7 \\
\hline $500-1000 \mu \mathrm{m}$ & Crushed & 4.8 & 2.0 & 58.3 \\
\hline$>1000 \mu \mathrm{m}$ & Crushed & 12.8 & 6.8 & 46.9 \\
\hline GYP611 blue & Whole rock & 3.3 & 1.7 & 48.5 \\
\hline Green & Whole rock & 10.9 & 1.0 & 90.8 \\
\hline White & Whole rock & 0 & 0.2 & - \\
\hline White & Whole rock & 0.1 & 0.2 & - \\
\hline Green & Whole rock & 38.2 & 8.6 & 77.5 \\
\hline GAB004 white & Whole rock & 0 & 0.2 & - \\
\hline Orange & Whole rock & 17.0 & 4.3 & 74.7 \\
\hline Green & Whole rock & 19.9 & 6.3 & 68.3 \\
\hline PM white & Whole rock & 0 & 0.2 & - \\
\hline Orange & Whole rock & 12.2 & 6.7 & 45.1 \\
\hline Green & Whole rock & 36.1 & 14.7 & 59.3 \\
\hline
\end{tabular}

but fall between 430-480, 650-670 and 910-940 nm (Sherman \& Waite 1985; Crowley et al. 2003). While in laboratory data, the differences in band structure of the $\sim 670 \mathrm{~nm}$ feature are well defined between iron minerals and chlorophyll, quantitative band depth analysis makes little distinction between these features. However, distinguishing between chlorophyll bearing samples and ferric iron-bearing minerals can be done by taking into consideration the strong $900 \mathrm{~nm}$ feature in conjunction with the $\sim 670 \mathrm{~nm}$ feature. Spectra of iron oxyhydroxides with a prominent $\sim 670 \mathrm{~nm}$ feature will always also have a strong feature at $900 \mathrm{~nm}$. With this in mind, should the $\sim 670 \mathrm{~nm}$ feature be present without the $900 \mathrm{~nm}$ feature it is reasonable to interpret that it could be due to chlorophyll and not to ferric oxyhydroxides.

The preservation of these chlorophyll spectral biosignatures is particularly relevant when considering the selection of UV/VIS filters for future Mars missions with astrobiological goals, such as the 2018 ESA ExoMars mission. The optimization of the filter wavelengths for the detection of this biosignature, combined with a tool for removing the upper layer of a rock to expose 'fresh' sample, could allow for the unambiguous identification of the chlorophyll molecule should it be present and preserved. While all of the proposed Exomars filters (Table 1) have more filters than the Pancam and Mastcam, wavelength position of the filters is key for chlorophyll detection The best likelihood for unambiguous detection is with the proposed PHYLL filter set which has six band passes in the $\sim 600-800 \mathrm{~nm}$ range in which the details of the chlorophyll spectral feature are found (Table 1). The ExoMars mission also provides the highest probability of unambiguous detection of endolithic chlorophyll with the Ma_Miss (Mars Multispectral Imager for Subsurface Studies) instrument, a miniaturized VIS-NIR spectrometer with $20 \mathrm{~nm}$ resolution from 400 to $2200 \mathrm{~nm}$ (De Angelis et al. 2013). This instrument will be integrated with the ExoMars drill to allow for acquisition of spectra from the subsurface. To acquire spectra from within drill holes it houses a $5 \mathrm{~W}$ light source and viewing geometry at right angles to the direction of drilling (i.e. the side of the drill holes). The ExoMars $532 \mathrm{~nm}$ Raman spectrometer (Edwards et al. 2012) will also be capable of chlorophyll 
detection. Chlorophyll fluoresces strongly when excited by a $532 \mathrm{~nm}$ laser, which will be strongly present even in low abundance in the 3000-4000 Raman-shift region and will likely give less ambiguous detection than the vibrational spectra at likely low abundances.

In regards to instruments presently on Mars, the Pancam instruments on the MER rovers and the MSL Mastcam are both capable of detecting the chlorophyll $670 \mathrm{~nm}$ spectral feature with band depth calculations indicating sensitivity and detection limits compared with that of laboratory spectra. Additionally, MSL is equipped with other more sensitive instrumentation with the ability to detect organic molecules. Should the chlorophyll molecule be present on Mars, it should be detectable using the Sample Analysis at Mars (SAM) and potentially via passive reflectance via the VNIR spectrometer on the LIBS portion of the ChemCam instrument given high enough concentrations (Summons et al. 2011).

\section{Summary and conclusions}

We have demonstrated that the chlorophyll spectral biosignature associated with cyanobacteria and algae from two Martian analogue sites is preserved following desiccation at $100 \mathrm{mb}$, with an anoxic, $\mathrm{CO}_{2}$ atmosphere and UV irradiation at the equivalent of $\sim 300$ years of present Mars UVC and UVB surface conditions. This preservation is proposed to be due to primarily to the UV-shielding effects of minerals, such as gypsum that dominates the LSM impact crater evaporite deposit and is precipitated at the EGC spring system with halite and calcite. Increased preservation of the chlorophyll spectral signature correlates with the presence of gypsum. However, unambiguous detection requires the exposure of the community because the endolithic niche of the organisms allows too little light to penetrate to their depth to lead to a measurable chlorophyll spectrum, thus masking the $670 \mathrm{~nm}$ feature. We show that the present multispectral imaging systems on Mars missions (Pancam and Mastcam) have the potential to detect this chlorophyll feature if it is preserved and freshly exposed, but that an absorption feature in that range may also be due to $\mathrm{Fe}^{3+}$ bearing minerals. Characterization of the mineralogical context of the sample is imperative as is the use of multiple spectral parameters.

The spatial distribution and mineral associations of the chlorophyll spectral signature at EGC has provided insights for orbital and rover-based investigations of potential spring deposits on Mars. We find that the chlorophyll spectral signature is more prevalent in samples taken closest to the main spring mound and outwash stream. If there is an opportunity in future rover exploration missions to analyse a spring deposit with reflectance spectroscopy, we suggest that spring vent peripheries and evaporite-rich lake deposits may have the highest potential for a positive identification of the chlorophyll $a$ spectral signature. As well, for such a deposit, the multispectral filters on the MER Pancam are comparable with those of the MSL Mastcam instrument. The chlorophyll molecule, present in our endolith and spring deposit samples exhibits a high degree of spectral preservation and persistence when exposed to Mars-like surface conditions, making it a viable target for Mars astrobiological exploration. As well, the presence of gypsum in veins at Endeavour crater (Squyres et al. 2012) makes this study of high relevance for ongoing rover missions.

\section{Acknowledgements}

The authors acknowledge the support of the CSA, NSERC, CREATE CATP, UW, MRIF, CFI; in addition, the two anonymous reviewers for their incisive critiques of the manuscript and for suggestions that resulted in major improvements.

\section{References}

Allen, C.C. \& Oehler, D.Z. (2008). A case for ancient springs in Arabia Terra, Mars. Astrobiology 8(738), 1093-1112.

Aubrey, A., Cleaves, H.J., Chalmers, J.H., Skelley, A.M., Mathies, R.A., Grunthaner, F.J., Ehrenfreund, P. \& Bada, J.L. (2006). Sulfate minerals and organic compounds on Mars. Geology 34(5), 357-360.

Baker, A.J. \& Louda, J.W. (1986). Porphyrins in the geological record. In Biological Markers in the Sedimentary Record, ed. Johns, R.B., pp. 125-225. Elsevier, Amsterdam.

Baker, V.R., Strom, G., Gulick, V.C., Kargel, J.S., Komatsu, G. \& Kale, V.S. (1991). Ancient oceans, ice sheets and the hydrological cycle on Mars. Nature 352, 589-594.

Bannatyne, B.B. (1959). Gypsum-anhydrite deposits of Manitoba. Manitoba Mines Branch 258, 46.

Bannatyne, B.B. \& McCabe, H.R. (1984). Manitoba crater revealed. GEOS 13, 10-13.

Barbieri, R. \& Stivaletta, N. (2011). Continental evaporites and the search for life on Mars. Geol. J. 46, 513-524.

Battler, M.M., Osinski, G.R. \& Banerjee, N.R. (2013a). Mineralogy of saline perennial cold springs on Axel Heiberg Island, Nunavut, Canada and implications for spring deposits on Mars. Icarus 224, 364-381.

Battler, M.M. et al. (2013b). Characterization of acidic cold seep emplaced jarositic Golden Deposit, NWT, Canada, as an analogue for jarosite deposition on Mars. Icarus 224, 382-398.

Bell, J.F. III et al. (2003). Mars Exploration Rover Athena Panoramic Camera (Pancam) investigation. J. Geophys. Res. 108(12), 1-30.

Bell, J.F. III, Joseph, J., Sohl-Dickstein, J.N., Arneson, H.M., Johnson, M.J., Lemmon, M.T. \& Savransky, D. (2006). In-flight calibration and performance of the Mars Exploration Rover Panoramic Camera (Pancam) instruments. J. Geophys. Res. 111, E02S03, doi:10.1029/ 2005JE002444.

Bell, J.F. III, Malin, M.C., Caplinger, M.A., Ravine, M.A., Godber, A.S., Jungers, M.C., Rice, M.R. \& Anderson, R.B. (2012). Mastcam Multispectral Imaging on the Mars Science Laboratory Rover: Wavelength Coverage ad Imaging Strategies at the Gale Crater Field Site. 43rd Lunar and Planetary Science Conf., abstract no. 2541.

Berard, G. et al. (2013). A hypersaline spring analogue in Manitoba, Canada for potential ancient spring deposits on Mars. Icarus 224, 399-412.

Berg, J.M., Tymoczko, J.L. \& Stryer, L. (2002). Biochemical evolution. In Biochemistry, 5th edn. W.H. Freeman, New York.

Bernstein, M.P., Sandford, S.A., Allamandola, L.J., Gillette, J.S., Clemett, S. J. \& Zare, R.N. (1999). UV irradiation of polycyclic aromatic hydrocarbons in ices: production of alcohols, quinones, and ethers. Science 283, 1135-1138.

Bibring, J.-P. et al. (2005). Mars surface diversity as revealed by the OMEGA/Mars Expreess observation. Science 307, 1576-1581. 
Bishop, J.L., Louris, S.K., Rogoff, D.A. \& Rothschild, L. (2006). Nanophase iron oxides as a key ultraviolet sunscreen for ancient photosynthetic microbes. Int. J. Astrobiol. 5, 1-12.

Buick, R. (2008). When did oxygenic photosynthesis evolve? Phil. Trans. R. Soc. B 363, 2731-2743.

Burr, D.M., Grier, J.A., McEwen, A.S. \& Keszthelya, L.P. (2002). Repeated aqueous flooding from the Cerberus Fossae: evidence for very recently extant, deep groundwater on Mars. Icarus 159, 53-73.

Cady, L.S., Farmer, J.D., Grotzinger, J.P., Schopf, J.W. \& Steele, A. (2003). Morphological biosignatures and the search for life on Mars. Astrobiology 3(2), 351-268.

Clark, R.N. \& Roush, T.L. (1984). Reflectance spectroscopy: quantitative analysis techniques for remote sensing applications. J. Geophys. Res. 89, 6329-6340.

Cloutis, E.A. et al. (2006). Detection and discrimination of sulfate minerals using reflectance spectroscopy. Icarus 184, 121-157.

Cloutis, E.A., Craig, M.A., Mustard, J.F., Kruzelecky, R.V., Jamroz, W.R., Scott, A., Bish, D.L., Poulet, F., Bibring, J-P. \& King, P.L. (2007). Stability of hydrated minerals on Mars. Geophys. Res. Lett. 34, L20202.

Cloutis, E.A., Berard, G., Mann, P. \& Stromberg, J. (2011). The gypsumville - Lake St. Martin impact structure: shoched carbonates, intracrater evaporited and cryptoendoliths. LPSC LXII. abstract no. 6009.

Cockell, C.S., Catling, D.C., Davis, W.L., Snook, K., Kepner, R.L., Lee, P. \& McKay, C.P. (2000). The ultraviolet environment of Mars: biological implications past, present, and future. Icarus 146, 343-359.

Cockell, C.S., Lee, P., Osinski, G., Horneck, G. \& Broady, P. (2002). Impact-induced microbial endolithic habitats. Meteorit. Planet. Sci. 37, $1287-1298$.

Cockell, C.S., Scheurger, A.C., Billi, D., Friedmann, E.I. \& Panitz, C. (2005). Effects of a simulated martian UV flux on the cyanobacterium, Chroococcidiopsis sp. 029. Astrobiology 5(2), 127-140.

Cockell, C.S., McKay, C.P., Warren-Rhodes, K. \& Horneck, G. (2008). Ultraviolet radiation-induced limitation to epilithic microbial growth in arid deserts - Dosimetric experiments in the hyperarid core of the Atacama Desert. J. Photochem. Photobiol. B 90, 79-87.

Cole, G.E. (1915). Report on the salt deposits of Canada and the salt industry. Report 325, Mines Branch, Canada.

Cousins, C.R., Griffiths, A.D., Crawford, I.A., Prosser, B.J., StorrieLombardi, M.C., Davis, L.E., Gunn, M., Coates, A.J., Jones, A.P. \& Ward, J.M. (2010). Astrobiological considerations for the selection of the geological filters on the ExoMars PanCam instrument. Astrobiology 10, 933-951.

Cousins, C.R., Gunn, M., Prosser, B.J., Barnes, D.P., Crawford, I.A., Griffiths, A.D., Davis, L.E. \& Coates, A.J. (2012). Selecting the geology filter wavelengths for the ExoMars Panoramic Camera Instrument. Planet. Space Sci. 71, 80-100.

Crowley, J.K., Williams, D.E., Hammartrom, J.M., Piatak, N., Chou, I-M. \& Mars, J.C. (2003). Spectral reflectance properties $(0.4-2.5 \mu \mathrm{m})$ of secondary $\mathrm{Fe}$-oxide, Fe-hydroxide, and Fe-sulphate-hydrate minerals associated with sulphide-bearing mine wastes. Geochem. Explor. Environ. Anal. 3, 219-228.

Dartnell, L.R., Desorgher, L., Ward, J.M. \& Coates, A.J. (2007). Modelling the surface and subsurface martian radiations environment: implications for astrobiology. Geophys. Res. Lett. 34, L02207.

Dartnell, L.R., Storrie-Lombardi, M.C. \& Ward, J.M. (2010). Complete fluorescent fingerprints of extremophilic and photosynthetic microbes. Int. J. Astrobiol. 9, 245-257.

Dartnell, L.R., Storrie-Lomardi, M.C., Mulineaux, C.W., Ruban, A.V., Wright, G., Muller, J-P. \& Ward, J.M. (2011). Degradation of cyanobacterial biosignatures by ionizing radiation. Astrobiology 11, 997-216.

Dartnell, L.R., Page, K., Jorge-Villar, S.E., Wright, G., Munshi, T., Scowen, I.J., Ward, J.M. \& Edwards, H.G.M. (2012). Destruction of Raman biosignatures by ionizing radiation and the implications for life detection of Mars. Anal. Bional. Chem. 403, 131-144.

De Angelis, S. et al. (2013). A VIS-NIR laboratory spectral library of terrestrial Mars analogs: support for the ExoMars - Ma_Miss instrument. LPSC XXIV, abstract no. 1544.
Edwards, H.G.M., de Oliveira, L.F.C., Cockell, C.S., Ellis-Evans, J.C. \& Wynn-Williams, D.D. (2004). Raman spectroscopy of senescing snow algae: pigmentation changes in an Anarctic cold desert extremophile. Int. J. Astrobiol. 3, 125-129.

Edwards, H.G.M., Hutchinson, I. \& Ingley, R. (2012). The ExoMars Raman spectrometer and the identification of biogeological spectroscopic signatures using a flight-like prototype. Anal. Bioanal. Chem. 404, 1723-1731.

Ehlmann, B.K. \& Mustard, J.R. (2012). An in-situ record of major environmental transitions on erly Mars at Northeast Syrtis Major. Geophys. Res. Lett. 39, L11202, doi:10.1029/2012GL051594.

Farmer, J.D. \& Des Marias, D.J. (1999). Exploring for a record of ancient Martian life. J. Geophys. Res. 104(E11), 977-995.

Fassett, C.I., Dickson, J.L., Head, J.W., Levy, J.S. \& Marchant, D.R. (2010). Supraglacial and proglacial valleys on Amazonian Mars. Icarus 208, 86-100.

Foster, I.S., King, P.L., Hyde, B.D. \& Southam, G. (2010). Characterization of halophiles in natural $\mathrm{MgSO}_{4}$ salts and laboratory enrichment samples: astrobiological implications for Mars. Planet. Space Sci. 58, 599-615.

Friedmann, E.I. (1982). Endolithic microorganisms in the Antarctic cold desert. Science 215, 1045-1053.

Gendrin, A. et al. (2005). Sulfates in martian layered terrains: the OMEGA/ Mars Express View. Science 307, 1587-1589.

Ghaemi, F.T. (2009). Design and fabrication of lenses for the color science cameras aboard the Mars Science Laboratory rover. Opt. Eng. 48, 103002.

Gomez, F. et al. (2011). Multidisciplinary integrated field campaign to an acidic martian Earth analogue with astrobiological interest: Rio Tinto. Int. J. Astrobiol. 10, 291-305.

Gómez, F., Ródriguez-Manfredi, J.A., Ródriguez, N., FernándezSampedro, M., Caballero-Castrejón, F.J. \& Amils, R. (2012). Habitability: were to look for life? Halophilic hábitats: earth analogs to study Mars habitability. Planet. Space Sci. 68(1), 48-55.

Grasby, S.E. (2000). Saline spring geochemistry, West-Central Manitoba. Report of Activities 2000, Manitoba Industry, Trade and Mines, Manitoba Geological Survey, pp. 214-216.

Grasby, S.E. \& Londry, K.L. (2007). Biogeochemistry of hypersaline springs supporting a mid-continent marine ecosystem: an analogue for Martian springs? Astrobiology 7, 662-683.

Grasby, S.E., Allen, C.C., Longazo, T.G., Lisle, J.T., Griffin, D.W. \& Beauchamp, B. (2003). Supraglacial sulfur springs and associated biological activity in the Canadian high artic-signs of life beneath the ice. Astrobiology 3, 583-596.

Grasby, S.E., Bezys, R. \& Londry, K.L. (2006). Silica 'chimneys' related to paleo-brine discharge from the Williston Basin. J. Geochem. Explor. 89, $149-152$.

Head, J.W. III, Hiesinger, H., Ivanov, M.A., Kreslavsky, M.S., Pratt, S. \& Thomas, B.J. (1999). Possible ancient oceans on Mars: evidence from Mars Orbiter Laser Altimeter Data. Science 286, 2134-2137.

Head, J.W. III, Marchant, D.R., Dickson, J.L., Kress, A.M. \& Baker, D.M. (2009). Northern mid-latitude glaciation in the late Amazonian period of Mars: criteria for the recognition of debris-covered glacier and valley glacier landsystem deposits. Earth Planet. Sci. Lett. 294, 306-320.

Hughes, K.A. \& Lawley, B. (2003). A novel Anarctic microbial community within gypsum crusts. Environmental Microbiology 5(7), 555-565.

Janssens, M.J., Hertogen, J., Takahiashi, H., Anders, E. \& Lambert, P. (1977). Rochechouart impact crater: identification of projectile. J. Geophys. Res. 82, 750-758.

Johnson, A.P., Pratt, L.M., Vishnivetskaya, T., Pfiffner, S., Bryan, R.A., Dadachova, E., Whyte, L., Radtke, K., Chan, E., Tronick, S., Borgonie, G., Mancinelli, R.L., Rothschild, L.J., Rogoff, D.A., Horikawa, D.D. \& Onstott, T.C. (2011). Extended survival of several organisms and amino acids under simulated martian surface conditions. Icarus 211, 1162-1178.

King, P.L. \& McLennan, S.M. (2010). Sulfur on Mars. Elements 6, 107-112. Kminek, G. \& Bada, J.L. (2006). The effect of ionizing radiation on the preservation of amino acids on Mars. Earth Planet. Sci. Lett. 245, $1-5$. 
Lambert, A., James, T.S. \& Thorleifson, L.H. (1998). Combining geomorphological and geodetic data to determine postglacial tilting in Manitoba. J. Paleolimnol. 19, 365-376.

Langevin, Y., Poulet, F., Bibring, J-P. \& Gondet, B. (2005). Sulfates in the north polar region of Mars detected by OMEGA/Mars Express. Science 307, 1584-1586.

Leybourne, M.I., Denison, R.E., Cousens, B.L., Bezys, R.K., Gregoire, D. C., Boyle, D.R. \& Dobrzanski, E. (2007). Geochemistry, geology, and isotopic ( $\mathrm{Sr}, \mathrm{S}$, and $\mathrm{B}$ ) composition of evaporites in the Lake St. Martin impact structure: New constraints on the age of melt rock formation. Geochem. Geophys. Geosys. 8, Q03001, doi:10.1029/2006GC001481.

Malin, M.C. \& Edgett, K.S. (2000). Evidence for recent groundwater seepage and surface runoff on Mars. Science 288, 2330-2335.

Malin, M.C. et al. (2010). The Mars Science Laboratory (MSL) mast-mounted Cameras (Mastcams) flight instruments. Lunar LPSCXLI. Abstract no. 1123.

Manicelli, R.L., Fahlen, T.F., Landheim, R. \& Klovstad, M.R (2004). Brines and evaporites: analogs for martian life. Adv. Space Res. 33, 1244-1246.

Marlow, J.J., Martins, Z. \& Sephton, M.A. (2011). Organic host analogues and the search for life on Mars. Int. J. Astrobiol. 10(1), 33-44.

Marshall, C.P., Carter, E.A., Leuko, S. \& Lavaux, E.J. (2006). Vibrational spectroscopy of extant and fossil microbes: relevance for the astrobiological exploration of Mars. Vib. Spectrosc. 41, 182-189.

McCabe, H.R. \& Bannatyne, B.B. (1970). Lake St. Martin crypto-explosion crater and geology of surrounding area. Geol. Surv. Manitoba 3, 70, 79.

Murchie, S.L. et al. (2009). A synthesis of Martian aqueous mineralogy after one Mars year of observations from the Mars Reconnaissance Orbiter. J. Geophys. Res., 114, E00D07, doi:10. 1029/2009JE003344.

Mustard, J.F. et al. (2008). Hydrated silicate minerals on Mars observed by the Mars Reconnaissance Orbiter CRISM instrument. Nature 454, 305-309.

Parnell, J. (2005). Plate tectonics and the detection of land-based biosignatures on Mars and extrasolar planets. Int. J. Astrobiol. 4, 175-186.

Parnell, J. et al. (2007). Searching for life on Mars: selection of molecular targets for ESA's Aurora ExoMars mission. Astrobiology 7, 578-604.

Pullan, D. et al. (2008). Identification of morphological biosignatures in martian analogue field specimens using in situ planetary instrumentation. Astrobiology 3(1), 119-156.

Quesada, A., Vincent, W.F. \& Lean, D.R.S. (1999). Community and pigment structure of Arctic cyanobacterial assemblages: the occurrence and distribution of UV-absorbing compounds. FEMS Microb. Ecol. 28, 315-323.

Rice, M.S., Bell, J.F. III, Cloutis, E.A., Wang, A., Ruff, S.W., Craig, M.A., Bailey, D.T., Johnson, J.R., de Souza, P.A. Jr. \& Farrand, W.H. (2010). Silica-rich deposits and hydrated minerals at Gusev crater, Mars: Vis-NIR spectral characterization and regional mapping. Icarus 205(2), 375-395.

Richardson, L.L. (1995). Remote sensing of algal bloom dynamics. BioScience 46(7), 492-501.

Rossi, A.P., Neukum, G., Pondrelli, M., van Gasselt, S., Zegers, T., Hauber, E., Chicarro, A. \& Foing, B. (2008). Large-scale spring deposits on Mars? J. Geophys. Res. 113, E08016.

Rothschild, L.J. (1990). Earth analogs for martian life. Microbes in evaporites, a new model system for life on Mars. Icarus 88, 246-260.

Sagan, C., Thompson, W.R., Carlson, R., Gurnett, D. \& Hord, C. (1993). A search for life on Earth from the Galileo spacecraft. Nature 365, 715-721.

Schmieder, M., Jourdan, F., Tohver, E., Mayers, C., Frew, A. \& Cloutis, E. (2013). The age of the Lake Saint Martin impact structure (Manitoba, Canada). LPSC XXIV, abstract no. 2001.
Schopf, J.W., Farmer, J.D., Foster, I.S., Kudryavtsev, A.B., Gallardo, V.A \& Espinoza, C. (2012). Gypsum-Permineralized Microfossils and Their Relevance to the Search for Life on Mars. Astrobiology 12(7), 618-633.

Schubert, B.A., Lowenstein, T.K. \& Timofeeff, M.N. (2009). Microscopic indentification of prokaryotes in modern and Ancient Halite, Saline Valley and Death Valley, California. Astrobiology 9(5), 467-482.

Seager, S., Turner, E.L., Schafer, J. \& Ford, E.B. (2005) Microscopic identification of prokaryotes in modern and ancient halite, Saline Valley and Death Valley, California. Astrobiology 5(3), 372-389.

Sherman, D.M. \& Waite, T.D. (1985). Electronic spectra of $\mathrm{Fe}$ $\mathrm{Fe}^{3+}$ oxides and oxide hydroxides in the near IR to near UV. $\mathrm{Am}$. Mineral. 70, 1262-1269.

Sinha, R.P., Richter, P., Faddoul, J., Braun, M. \& Hader, D-P. (2002). Effects of UV and visible light on cyanobacteria at the cellular level. Photochem. Photobiol. Sci. 1, 553-559.

Spencer, R.J. 2000. Sulfate minerals in evaporite deposits. Rev. Mineral. Geochem. 40, 173-192.

Stivaletta, N. \& Barbieri, R. (2009). Endolithic microorganisms from spring mound evaporite deposits (southern Tunisia). J. Arid Environ. 73, $33-39$.

Stivaletta, N., Barbieri, R., Marinageli, L., Ori, G.G. \& Bosci, M. (2005). Fossil endolithic cyanobacteria in evaporates: implications for the astrobiological exploration. 36th Lunar and Planetary Science Conf., League City, Texas, USA, abstract no. 1354.

Stivaletta, N., López-García, P., Boihem, L. \& Barbieri, R. (2010). Biomarkers of endolithic communities within gypsum crusts (southern Tunisia). Geomicrobiol. J. 27, 101-110.

Squyres, S.W. et al. (2004). In situ evidence for an ancient aqueous environment at Meridiani Planum, Mars. Science 306, 1709-1714.

Squyres, S.W. et al. (2012). Ancient impact and aqueous processes at Endeavour Crater, Mars. Science 336, 570-576.

Summons, R.E., Amend, J.P., Bish, D., Buick, R., Cody, G.D., Des Marais, D.J., Bromart, G., Eigenbrode, J.L., Knoll, A.H. \& Sumner, D.Y. (2011). Preservation of martian organic and environmental records: final report of the Mars biosignature working group. Astrobiology 11(2), 157-181.

Suo, Z., Avci, R., Schweitzer, M.H. \& Deliorman, M. (2007). Porhyrin as an ideal biomarker in the search for Extraterrestrial Life. Astrobiology 7(4), 605-615.

Taiz, L. \& Zeiger, E. (2010). Photosynthesis: the light reactions. In Plant Physiology, 5th edn. Sinaur Associates Inc., Sunderland, MA, USA. pp. 114.

Vishnivetskaya, T.A., Sprina, E.V., Shatilovich, A.V., Erokhina, L.G., Vorobyova, E.A. \& Gilichinsky, D.A. (2003). The resistance of viable permafrost algae to simulated environmental stresses: implications for astrobiology. Int. J. Astrobiol. 2, 171-177.

Vreeland, R.H., Rosenzwelg, W.D. \& Powers, D.W. (2000). Isolation of a 250 million-year-old halotolerant bacterium from a primary salt crystal. Nature 407, 897-900.

Wardlaw, N.C., Stauffer, M.R. \& Hoque, M. (1969). Striations, giants grooves, and superposed drag folds, Interlake area, Manitoba. Can. J. Earth Sci. 6(4), 577-593.

Weirzchos, J., Ascaco, C. \& McKay, C. (2006). Endolithic cyanobacteria in halite rocks from the hyperarid core of the Atacama desert. Astrobiology 6(4), 1-7.

Wray, J.J. et al. (2011). Columbus crater and other possible groundwater-fed paleolakes of Terra Sirenum, Mars. J. Geophys. Res. 116, 1-41.

Wynn-Williams, D.D., Edwards, H.G.M., Newton, E.M. \& Holder, J.M. (2002). Pigmentation as a survival strategy for ancient and modern photosynthetic microbes under high ultraviolet stress on planetary surfaces. Int. J. Astrobiol. 1(1), 39-49. 